\title{
Contrastación teórica y empírica de la teoría neoclásica y la teoría marxiana sobre la relación entre el trabajo cualificado, la productividad y el salario
}

\author{
Yusef Ali BuKele Ortez \\ César Enrique Marroquín Rivas \\ Juan Carlos Méndez Funes \\ Edgar Romeo Rodríguez HerRera \\ Universidad Centroamericana "José Simeón Cañas"
}

"Podrán cortar todas las flores, pero nunca terminarán con la primavera" Che.

En memoria del Dr. Armando Bukele

Resumen: Debido a las deficiencias actuales en el estudio de la relación entre el trabajo cualificado, la productividad y el salario, se creyó necesario estudiar estas variables bajo dos teorías diferentes, la neoclásica y la marxiana. Se analizaron estas variables mediante la creación de modelos estadísticos y series de tiempo con el programa Stata. Los resultados reflejaron que una distribución más equitativa del ingreso generaría una mejora significativa y comprobable en el desarrollo económico de los dos países estudiados (El Salvador y Estados Unidos); por lo tanto, se recomienda una mayor intervención estatal en la regulación de la renta. También se comprobó estadísticamente que, entre las dos teorías, la teoría marxiana tiene un mayor nivel explicativo de estas variables y sus relaciones; por lo que sugerimos que en estudios posteriores se utilice un enfoque basado en esta teoría.

Abstract: Due to the current deficiencies in the study of the relationship between skilled labor, productivity and wages, it was thought necessary to study these variables under two different theories, Neoclassical and Marxian. These variables were analyzed using statistical models and time series with the Stata program. Results showed that a more equitable distribution of income would generate a significant and measurable improvement in the economic development of the two countries under study (El Salvador and the United States); therefore, greater state intervention in the regulation of income is recommended. Statistically, it was also found 
that, between the two theories, the Marxian theory explains these variables and their relationships better; because of this, we suggest that future studies base their approach using this theory.

\section{Palabras claves}

Economía, teoría económica marxista, teoría económica neoclásica, El Salvador, salario, productividad

\section{Keywords}

Economics, Marxist Economical Theory, Neoclassic Economical Theory, El Salvador, Income, Productivity

\section{Introducción}

Tanto en El Salvador como en Estados Unidos se han realizado estudios sobre la medición del trabajo cualificado y su relación con la productividad y el salario. El problema radica en que estos estudios se han realizado solamente desde una misma perspectiva, utilizando la teoría neoclásica. De ahí la necesidad de realizar estudios que consideren otras corrientes de pensamiento, como la marxiana. Tal estudio comparativo ofrece la posibilidad de medir el poder explicativo que tienen estas teorías y, a partir de ello, realizar recomendaciones de políticas económicas más adecuadas. Es esta justamente la finalidad del presente trabajo. En el primer capítulo se abordan aspectos teóricos de ambas teorías; en el segundo, se realiza una contrastación empírica a partir de datos de El Salvador y Estados Unidos; en el tercer capítulo, se desarrollan las implicaciones sociales y de política económica en ambos países de acuerdo a los resultados obtenidos; y finalmente, se presentan las conclusiones y reflexiones obtenidas a partir de estos resultados.

\section{Capítulo I}

\section{Aspectos teóricos del enfoque neoclásico y marxiano sobre la relación entre el trabajo cualificado, la productividad y el salario}

\subsection{La teoría neoclásica}

Para los economistas clásicos (A. Smith, D. Ricardo, entre otros.) el trabajo era la fuente del valor de las mercancías y de la riqueza de la sociedad. A mediados del siglo XIX, esta teoría laboral del valor fue vista como "peligrosa", ya que podía conducir a cuestionar la apropiación del excedente de la clase capitalista. Es de esta crítica y desacreditación que la Escuela Marginalista, y su teoría del valor subjetiva (la utilidad marginal), se convierte en el pensamiento económico dominante. 
Más tarde (a finales del siglo XIX), esta corriente evolucionaría hasta convertirse en la hoy denominada Escuela Neoclásica, con aportes de reconocidos autores como William Stanley Jevons, Leon Walras, Carl Menger, Alfred Marshall, Eugen von Böhm-Bawerk y Wilfredo Pareto, entre otros.

El valor, de acuerdo a esta escuela, proviene de la 'utilidad', concepto abstracto de difícil medición asociado con las 'preferencias' del consumidor. Esta utilidad dependería pues de la capacidad de satisfacer necesidades humanas provenientes del "estómago" o de la "fantasía". Además, esta presentaría un comportamiento positivo pero decreciente, lo que explica por qué el incremento progresivo del consumo de un bien provoca, en un determinado momento, que ya no se desee más.

La función de producción neoclásica es la relación entre los factores productivos ${ }^{1}$ y el producto obtenido por la combinación de estos. Esta función es necesaria para conocer el comportamiento de la productividad marginal (Pmg) de cada uno de los factores de la producción, capital (K) y trabajo (L). En el corto plazo, suponemos que uno de los factores es fijo, el capital. Será el factor trabajo el que determinará el flujo de producción total [1] $Q=F(L)$; mientras que, en el largo plazo, todos los factores varían, entonces, los incrementos en la producción se verán reflejados en la distinta combinación de los factores productivos, en este caso $\mathrm{K}$ y $\mathrm{L}[2] Q=F(K, L)$. De acuerdo a esta visión, a medida que se incrementa la productividad se incrementa también el salario. El salario es considerado como el precio del trabajo, y su cálculo está asociado a la oferta y demanda de este factor.

En el mercado de trabajo sucede que el precio de cierta capacidad no tiene ninguna relación inherente a su valor social, este depende fundamentalmente de su escasez. De ahí la interrogante, por ejemplo: ¿Por qué Lionel Messi o Cristiano Ronaldo ganan mucho más que el mejor neurocirujano del mundo, a pesar de que el trabajo del neurocirujano es mucho más trascendental y complicado que patear una pelota de fútbol? Esto es así debido a que hay un gran número de neurocirujanos que pueden hacer un trabajo similar, pero no hay muchas personas que jueguen como Messi o Ronaldo. En contraste, los salarios de empleos que requieren de poca o nula capacitación son bajos debido a que hay una enorme cantidad de personas que pueden realizarlos.

Uno de los principales aportes de la teoría neoclásica a la economía laboral es la teoría del capital humano. Desde esta visión, la relación entre el trabajador y el empresario se reduce a una relación entre cosas, ya que el trabajo es 
un factor más dentro del proceso productivo, que se combina con el capital (maquinaria, equipos, entre otros.). Dicha teoría fue formulada inicialmente por Theodore Schultz en 1961, pero fue hasta 1964 que la teoría del capital humano se presenta de manera formal por Gary Becker en su obra Human Capital, publicada ese mismo año. En esencia, esta teoría muestra la idea básica de considerar la educación y formación como inversiones que realizan los individuos racionales con el fin de incrementar su eficiencia productiva y sus ingresos. Así, Schultz, Gary Becker y Jacob Mincer afirman que la heterogeneidad de los trabajadores ${ }^{2}$ obedece a los diferentes grados de inversión dedicados a la formación y adquisición de su determinada cualificación. Además, su retribución económica (salarios) tiene una relación directa con su nivel de formación. El trabajo desaparece como factor independiente dentro del proceso productivo y se define también como capital. En otras palabras, es el "capital" con el que cuentan los trabajadores. Dicho capital, se define como la suma total de habilidades personificadas en un individuo: educación, inteligencia, carisma, creatividad, perseverancia, experiencia laboral, salud, entre otros. De esta manera, se puede dividir el capital humano entre habilidades innatas y adquiridas. Las habilidades innatas son aquellas actitudes físicas e intelectuales con las que nacen las personas, mientras que las adquiridas son aquellas que se obtienen a lo largo de la vida: educación formal, educación informal y experiencia laboral.

Jacob Mincer (1974) es considerado un pionero en el estudio de la relación que existe entre el capital humano y los retornos de los ingresos provocados por los mayores niveles de educación. La ecuación básica minceriana puede expresarse como: [5] lnw $=\beta_{0}+$ $\beta_{1}$ educ $+\beta_{2} \exp +\beta_{3} \exp ^{2}+\epsilon$. ${ }^{3}$ Según esta teoría, los parámetros que se relacionan con la educación y la experiencia deben ser positivos, es decir, $\beta_{1}$ y $\beta_{2}$ y; en cambio, el parámetro que se relaciona con la experiencia potencial $\beta_{3}$, es positivo pero tiene un comportamiento decreciente.

\subsection{Teoría marxiana}

En 1867 Carlos Marx publica su obra El Capital, subtitulada Crítica de la economía política. En ella, realiza justamente eso, una crítica a la economía política clásica de Ricardo, Smith y Malthus, entre otros. Marx estudia la esencia del modo de producción capitalista, iniciando su análisis con la mercancía, en tanto es esta la forma elemental de aquel. Una mercancía es entendida como cualquier objeto fruto del trabajo cuyo destino es la venta, y que puede reproducirse en serie. Una mercancía tiene un valor de uso y un valor. El valor de uso es la capacidad que tiene un 
objeto para satisfacer una necesidad humana de cualquier clase. El valor, en cambio, se encuentra determinado por el trabajo que ha sido necesario para producir esa mercancía. Este valor posee sustancia (trabajo social abstracto), magnitud (cantidad de tiempo de trabajo socialmente necesario) y forma (valor de cambio). El trabajo posee a su vez un doble carácter: concreto y abstracto. El trabajo concreto es el creador del valor de uso de una mercancía, y se trata de una actividad productiva específica para producir una mercancía. En cambio, el trabajo abstracto "es aquel trabajo social, indistinto, indeterminado, indiferenciado, que implica un gasto de energía física y/o mental y que presupone la homogeneidad fisiológica" (Montoya, 2000, p. 56).

Es evidente que no todos los trabajos son iguales, es por ello que Marx diferencia el trabajo simple del trabajo complejo. El trabajo simple es el empleo de la fuerza física de trabajo que toda persona posee en promedio, y que no requiere de mayores capacidades adquiridas; y el trabajo complejo es el trabajo simple potenciado o multiplicado. Este sí requiere de una educación especial, de adiestramiento o de capacitación. Una hora de trabajo complejo puede equivaler a varias horas de trabajo menos complejo y a muchísimas horas de trabajo simple (Montoya, 2000, pp. 56-57). La fuerza de trabajo (FT), que no es lo mismo que trabajo, también es una mercancía; esta se define como "el conjunto de facultades físicas e intelectuales que existen en el cuerpo humano, en su personalidad viva, y que debe de ponerse en movimiento para producir cosas útiles" (Marx, 1980, p. 17). El precio del valor de la fuerza de trabajo es el salario, y hace referencia, como veremos a continuación, al valor del cúmulo de medios de vida que, en una sociedad específica y en un momento determinado, son necesarios para reproducir al trabajador y a su familia. El Dr. Mario Montesino es uno de los autores que más ha contribuido a la teoría de la cobertura del valor de la fuerza de trabajo. En su tesis doctoral desarrolla una aplicación basada en álgebra lineal para el análisis de la reproducción de la fuerza de trabajo y la eficiencia productiva. Ahí demuestra cómo, a medida que se incrementa la cobertura de la FT, las sociedades son más eficientes; mientras que lo contrario sucede con una cobertura insuficiente de esta.

En cuanto a la productividad, Marx (1980) afirma que esta es el recíproco del tiempo de trabajo socialmente necesario para la producción de un conjunto de mercancías; es decir, la productividad es el recíproco del valor del producto total. Un aumento en la productividad implica un incremento en la eficiencia de la 
producción de una determinada mercancía. Esto puede afectar la eficiencia de la producción de otras mercancías, y con ello la producción de todas las mercancías. La búsqueda de incrementar la productividad impulsa la mecanización del proceso productivo, sustituyendo FT por medios de producción (maquinaria, equipo, entre otros.) A la proporción entre el valor de los medios de producción y el valor de la fuerza de trabajo (VFT), Marx le denomina composición de valor, y a la proporción entre la masa de los medios de producción y la cantidad de trabajo empleada, composición técnica de capital. De esta relación es que surge la composición orgánica de capital. Al valor apropiado por el capitalista se le Ilama plusvalía. Para incrementar esta plusvalía los capitalistas recurren a dos mecanismos: el de la plusvalía relativa y el de la plusvalía absoluta. El mecanismo de plusvalía relativa se da cuando se incrementa la productividad, lo que disminuye el VFT mediante una disminución del valor de los medios de vida. En cambio, el mecanismo de plusvalía absoluta se da por medio de la prolongación de la jornada de trabajo, y/o por el incremento de la intensidad de este.

\subsubsection{El debate sobre el trabajo complejo}

Los críticos de Marx han discutido mucho sobre la teoría del trabajo complejo, acá piensan haber descubierto una contradicción de la teoría laboral del valor marxiana. Aseguran que Marx no fue capaz de definir la reducción del trabajo complejo a trabajo medio simple, y consideran que incurrió en un razonamiento circular en su teoría laboral del valor.

Se considera que el trabajo más complejo solo es igual al trabajo simple potenciado o más bien multiplicado, de suerte que una pequeña cantidad de trabajo complejo equivale a una cantidad mayor de trabajo simple (...) la experiencia demuestra que constantemente se opera esa reducción. Por más que una mercancía sea el producto del trabajo más complejo su valor la equipara al producto del trabajo simple y, por consiguiente, no representa más que una determinada cantidad de trabajo simple. (Marx, 1980, p. 55)

La explicación circular consistiría en afirmar que el valor de una mercancía está determinado por el VFT que se emplea para producirla. Así, para explicar el valor de un producto, simplemente se haría referencia al valor de la mercancía que lo produce, tal como Marx había criticado ya a otros autores, sin que se logre explicar 
nada verdaderamente. Fue Eugene von Böhm-Bawerk, uno de los principales críticos de Marx, quien lanza primero esta observación. Argumenta que el trabajo simple y el trabajo complejo son distintos. Marx estaría reduciendo el trabajo complejo a trabajo simple para compararlo, por lo que podemos decir que cinco productos de un trabajo simple equivalen a un producto de trabajo complejo, pero no son lo mismo porque contienen diferente trabajo incorporado, lo que estaría contradiciendo la teoría del valor de Marx, ya que todo se explicaría por medio de la relaciones de cambio y no por la cantidad de tiempo de trabajo socialmente necesario para su producción. Esto, de acuerdo a Böhm-Bawerk, deja en evidencia que Marx habría sido incapaz de explicar una contradicción en su propia teoría, y por eso se habría limitado a decir que el trabajo complejo se reduce a trabajo simple por medio de la experiencia (Rosdolsky, 2004, pp. 555-564).

\subsubsection{Nuestra contribución al debate}

Si bien Marx no explica exactamente cuánto más vale una hora de trabajo complejo en términos de una hora de trabajo simple, esto no es porque su teoría encierre una contradicción y/o porque lo haya hecho a propósito, como lo asevera Eugen Böhm-Bawerk, sino más bien porque la intención de Marx era la de explicar la esencia y funcionamiento del modo de producción capitalista de forma general, y no estrictamente el valor de una hora de trabajo complejo con respecto a una hora de trabajo simple. Acá se tratará de contribuir a desarrollar este tema. Para ello utilizaremos un pequeño ejemplo, altamente sintetizado, abordando una de las diversas formas en la cual se podría explicar este tema. Veamos el caso de dos personas a quienes denominaremos Carlos y Jaime. Partamos de los siguientes supuestos:

- Los dos son salvadoreños de nacimiento. Carlos es carpintero y produce sillas; mientras que Jaime, estudió ingeniería mecánica y produce relojes.

- Carlos y Jaime trabajan para una empresa capitalista, y ambos reciben un salario.

- Ambos realizan su actividad productiva bajo las condiciones medias de la sociedad imperante del siglo XXI. Los dos tienen la misma edad, poseen una educación y un conocimiento promedio dentro de sus respectivas ocupaciones, asimismo sus destrezas como sus habilidades están dentro del promedio.

- Las condiciones tecnológicas (o el grado de mecanización) y naturales son las medias dentro de la sociedad salvadoreña. 
- Las cosas se compran y se venden por su valor.

- Tanto Carlos como Jaime realizan su trabajo en una jornada laboral establecida por el Código de Trabajo de la República de El Salvador (2014), el cual establece que “(...) la semana laboral diurna no excederá de cuarenta y cuatro horas, ni la nocturna de treinta y nueve" (Cap. II, art. 161). Las horas de trabajo mensuales serían $176^{3}$.

El VFT es entendido como el valor del cúmulo de valores de uso que, en una sociedad determinada y en un momento determinado, las personas necesitan para reproducir su vida en condiciones normales. De forma estricta, esto es justamente el tiempo de trabajo socialmente necesario para la producción de la mercancía fuerza de trabajo. Tal valor debe incorporar lo que una persona (y su familia) gastan en alimentación, salud, alojamiento, recreación, educación, transporte, agua potable, energía eléctrica, etc. Por ello, un aproximado del VFT de un obrero sería el valor de la canasta de mercado ${ }^{4}$. En el siguiente cuadro se presenta la canasta de mercado de El Salvador en el año 2012.

\section{Cuadro 1. Valor de la fuerza de trabajo de Carlos}

\begin{tabular}{|l|r|r|r|}
\hline \multicolumn{1}{|c|}{ División } & Artículos & Ponderación & Unidades monetarias \\
\hline Alimentación y bebidas no alcohólicas & 71 & $26.28 \%$ & 216.16 \\
\hline Bebidas alcohólicas, tabaco y estupefacientes & 4 & $0.48 \%$ & 3.95 \\
\hline Prendas de vestir y calzado & 32 & $5.39 \%$ & 44.33 \\
\hline Alojamiento, agua, electricidad, gases y otros combustibles & 9 & $12.44 \%$ & 102.32 \\
\hline Muebles y artículos para el hogar & 26 & $7.77 \%$ & 63.91 \\
\hline Salud & 19 & $5.41 \%$ & 44.50 \\
\hline Transporte & 17 & $12.02 \%$ & 98.87 \\
\hline Comunicaciones & 5 & $4.13 \%$ & 33.97 \\
\hline Recreación y cultura & 28 & $6.87 \%$ & 56.51 \\
\hline Educación & 5 & $3.33 \%$ & 27.39 \\
\hline Restaurantes y hoteles & 6 & $8.24 \%$ & 67.78 \\
\hline Bienes y servicios diversos & 16 & $7.64 \%$ & 62.84 \\
\hline Total & $\mathbf{2 3 8}$ & $\mathbf{1 0 0 . 0 0 \%}$ & $\mathbf{8 2 2 . 5 3}$ \\
\hline
\end{tabular}

Fuente: Elaboración propia con base en DYGESTIC.

El costo de la canasta es actualizado mensualmente, por lo tanto calculamos el promedio de la canasta de mercado para el año 2012, que equivale a 822.53 unidades monetarias (U.M.) que representan el VFT. Entonces, para medir a cuántas horas de trabajo simple equivale una hora de trabajo complejo partimos, como Marx aconseja, del intercambio. 
En la sociedad mercantil (capitalista), la reducción de los trabajos cualificados a trabajo simple, es decir, su igualación en determinadas proporciones, no se lleva a cabo directamente como se haría en el caso de una sociedad planificada a partir de una unidad de medida previamente determinada. Se lleva a cabo indirectamente por medio de la igualación de los productos del trabajo en tanto que valores, por la igualación de las mercancías en el intercambio (Gill, 2002, p. 14). ${ }^{5}$

Luego de conocer el VFT de Carlos (carpintero) debemos preguntarnos: ¿a cuántas sillas equivale un reloj? ¿Cuál es el valor del reloj expresado en sillas? ¿Cuántas sillas y cuántos relojes, pueden producirse en una jornada de trabajo? Es en el intercambio donde las diferencias cualitativas se transforman en diferencias cuantitativas entre las dos mercancías producidas (sillas y relojes). Si un reloj que produce Jaime en promedio vale 200 U.M., y una silla que produce Carlos tiene un valor de 10 U.M., en términos promedio (de acuerdo a los precios por artículos en El Salvador, y suponiendo que las cosas se venden por su valor), Carlos tendría que dar 20 sillas por cada reloj.

Términos de intercambio $(T I)=\frac{\text { Valor monetario de un reloj }}{\text { Valor monetario de una silla }}=\frac{200 \mathrm{U} \cdot \mathrm{M} \cdot / \mathrm{reloj}}{10 \mathrm{U} \cdot \mathrm{M} / \text { silla }}=20$ sillas $/ \mathrm{reloj}$

Por consiguiente, Jaime intercambiará cinco centésimos (0.05) de reloj por cada silla producida por Carlos. Para generalizar cualquier mercancía que se intercambia vamos a denotar la siguiente fórmula: nmercancía $a_{i}=\mu \Psi_{\text {mercancía }} ; i=1,2$.

Donde:

1. $\Psi=$ Cantidades de la mercancía $i$ que se quieren comparar.

2. $\mu=$ Valor de la mercancía $i$ con respecto a la otra mercancía $i$.

3. Mercancía $i=$ mercancías que se intercambian. 


\begin{tabular}{|c|c|c|c|c|c|c|c|}
\hline (2) & The & 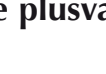 & la port & 012 & 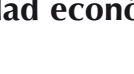 & 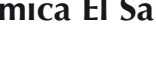 & 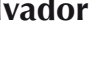 \\
\hline $\begin{array}{l}\text { Rama de } \\
\text { actividad } \\
\text { económica }\end{array}$ & $\begin{array}{c}\text { Salario } \\
\text { promedio } \\
\text { mensual }\end{array}$ & $\begin{array}{c}\text { Población } \\
\text { ocupada }\end{array}$ & $\begin{array}{c}\text { Remuneración } \\
\text { asalariados \$ }\end{array}$ & $\begin{array}{c}\text { PIB real año } \\
\text { base 2012=100 }\end{array}$ & $\begin{array}{l}\text { Porcentaje } \\
\text { del PIB }\end{array}$ & EBE millones \$ & $\begin{array}{l}\text { Tasa de } \\
\text { plusvalía }\end{array}$ \\
\hline $\begin{array}{l}\text { Industria } \\
\text { manufacturera }\end{array}$ & 264.78 & 397046 & 1261558078.56 & 5428995088.71 & 0.227493467 & 4167437010.15 & $330.34 \%$ \\
\hline $\begin{array}{l}\text { Comercio, } \\
\text { hoteles y } \\
\text { restaurantes }\end{array}$ & 258.13 & 734113 & 2273959064.28 & 4808127313 & 0.201476983 & 2534168248.27 & $111.44 \%$ \\
\hline
\end{tabular}

Fuente: Elaboración propia a partir de datos de la EHPM.

Ahora calculamos la tasa de plusvalía $^{6}$ para el año 2012 por rama de actividad económica (Ver cuadro anterior). En el sector industrial la tasa de plusvalor fue de $330.34 \%$, mientras que para el sector comercial, hoteles y restaurantes la tasa de plusvalía fue de
$111.44 \%$. A partir de la información anterior, obtenemos la plusvalía del empresario capitalista: 916.627432 U.M., aproximadamente. ${ }^{7}$

El valor nuevo creado mensualmente será por lo tanto:

Valor nuevo creado $=V+P v=822.53$ U.M. +916.627432 U.M. $=1,739.157432$ U.M.

Mensualmente se debe de generar 822.53 U.M., para pagarle al trabajador simple (capital variable) y para generar una valorización del capital variable del $111.44 \%$ Pero dentro del valor de la mercancía hay también una parte que se destina a la reposición del equipo, maquinaria, entre otros; es decir, el trabajo pasado que ha sido transferido a cada silla. Si mensualmente se producen 250 sillas, el capital constante será de 760.842568 U.M. ${ }^{8}$ Por cada hora de trabajo se producirán 1.420 sillas ${ }^{9}$. Para determinar el tiempo de trabajo en horas que utiliza Carlos para fabricar una silla, expresamos lo siguiente.

$$
\text { Tiempo por silla }=\frac{\text { una silla }}{\text { producción de sillas por hora }}=0.704 \text { horas }
$$

El tiempo de trabajo socialmente necesario para producir una silla será de 42 minutos con 14 segundos aproximadamente. Por lo tanto, Carlos producirá aproximadamente 62.50 sillas semanales y 250 sillas al mes, equivalentes a 2,500 U.M. Sabiendo que en 176 horas de trabajo simple $\left(\mathrm{H}_{1 \mathrm{~S}}\right)$ se genera el nuevo valor creado 
en 1,739.157432 U.M., podemos obtener el tiempo de trabajo necesario y el tiempo de trabajo excedente en que se divide la jornada mensual de trabajo de la siguiente forma:

$$
T L N=\frac{\text { Horas de trabajo mensual } x \text { VFT }}{\text { Valor nuevo creado }}=\frac{176 \text { horas } x 822.53 \text { U.M.M. }}{1,739.157432 \text { U.M. }}=83.23874385 H_{L S}
$$

Carlos, en 83 horas, 14 minutos y 19 segundos de tiempo necesario de trabajo simple cubre el valor de su fuerza de trabajo, lo que equivale a 1.89 semanas $^{10}$. Para obtener el tiempo de trabajo excedente: $T E=$ Horas de trabajo mensual $-T L N=92.76125615 H_{L S}$. El tiempo en el que se objetiva la plusvalía es de 92 horas, con 45 minutos y 40 segundos $^{11}$, equivalentes a 2.11 semanas. Si expresamos el capital variable en sillas al mes, obtenemos:

$V$ expresado en sillas $=\frac{\text { Valor de la fuerza de trabajo en U.M. }}{\text { Sillas expresadas en U.M. }}=\frac{822.53 \text { U.M. }}{10}=82.253$ Sillas

Entonces, serían 82.253 sillas que Carlos necesita producir para poder cubrir el valor de su fuerza de trabajo mensual, mientras que el tiempo de trabajo excedente en que se objetiva la plusvalía mensualmente sería el siguiente:

Pv expresado en sillas $=$ Sillas producidas mensualmente $-V$ expresado en sillas $=93.747$ Sillas

Exploremos ahora el caso del trabajo complejo. Marx (1980) lo define como el trabajo simple potenciado, en el que se han incurrido costos de formación.
Es necesario, entonces, calcular los gastos directos (privados) e indirectos (sociales) realizados para obtener un grado de especialización. 


\section{Cuadro 3. Valor de la fuerza de trabajo de Jaime}

\begin{tabular}{|l|c|c|}
\hline \multicolumn{1}{|c|}{ División } & Ponderación & Unidades monetarias \\
\hline Gastos privados & $96.88 \%$ & $3,078.38$ \\
\hline Alimentación y bebidas no alcohólicas & $25.46 \%$ & 809.00 \\
\hline Bebidas alcohólicas, tabaco y estupefacientes & $0.47 \%$ & 14.78 \\
\hline Prendas de vestir y calzado & $5.22 \%$ & 165.92 \\
\hline $\begin{array}{l}\text { Alojamiento, agua, electricidad, gases y otros } \\
\text { combustibles }\end{array}$ & $12.05 \%$ & 382.95 \\
\hline Muebles y artículos para el hogar & $7.53 \%$ & 239.19 \\
\hline Salud & $5.24 \%$ & 166.54 \\
\hline Transporte & $11.65 \%$ & 370.02 \\
\hline Comunicaciones & $4.00 \%$ & 127.14 \\
\hline Recreación y cultura & $6.66 \%$ & 211.48 \\
\hline Educación & $3.23 \%$ & 102.51 \\
\hline Restaurantes y hoteles & $7.98 \%$ & 253.66 \\
\hline Bienes y servicios diversos & $7.40 \%$ & 235.19 \\
\hline Gastos sociales & $3.12 \%$ & 99.10 \\
\hline Salud & $0.22 \%$ & 7.08 \\
\hline Transporte e infraestructura, entre otros & $0.01 \%$ & 0.43 \\
\hline Inversión por persona en educación & $0.37 \%$ & 11.80 \\
\hline Transferencias del estado & $2.51 \%$ & 79.78 \\
\hline Valor del grado del cualificación & $79.44 \%$ & $3,177.47$ \\
\hline Fuerza de trabajo (simple) & $20.56 \%$ & 822.53 \\
\hline Total & $100.00 \%$ & 4,000 \\
\hline
\end{tabular}

Fuente: Elaboración propia a partir de datos de la PNUD y la EHPM. ${ }^{12}$

Luego de haber calculado el VFT de Jaime, que equivale a 4,000 U.M., al mes, e incorporando un mayor grado de especialización debido a los costos de formación, es necesario definir cuál será el

Valor nuevo creado por mes $=V+P v=4,000$ U.M. $+13,213 \cdot 6$ U.M. $=17,213 \cdot 6$ U.M. valor nuevo creado por Jaime (teniendo en cuenta que la tasa de explotación del sector industrial es de $330.34 \%)$.

Este será: 
Entonces, para obtener la cantidad de los relojes producidos mensualmente (valor nuevo creado), hacemos lo siguiente:

Relojes producidos por mes $=\frac{V N C \text { por mes }}{\text { Valor por reloj }}=\frac{V+P v}{\text { Valor por reloj }}=\frac{17,213.6 \text { U.M. }}{200 \text { U.M. }}=86.068$

Por lo tanto, mensualmente Jaime (ingeniero mecánico) producirá 86.068 relojes para cubrir el valor creado; en cambio, Carlos (carpintero) solo alcanzará a producir 12.5 sillas mensualmente en las 176 horas de trabajo mensuales. ${ }^{13}$ Esto es así debido al grado de especialización del trabajo; por lo tanto, Jaime produce una mayor cantidad de valores de uso en una jornada de trabajo con respecto a Carlos.

Para obtener la producción de relojes por hora de trabajo complejo $\left(\mathrm{H}_{\mathrm{LC}}\right)$ :

$$
\text { Producción de reloj por } H_{L C}=\frac{Q \text { relojes producidos mensualmente }}{\text { Tiempo de trabajo mensual }}
$$

Producción de reloj por $H_{L C}=\frac{86.068 \text { relojes }}{176 \text { horas }}=0.4890227273 \frac{\text { reloj }}{\text { hora }}$

Por lo tanto, 0.49 relojes se producirán en una hora de trabajo complejo socialmente necesaria de Jaime. Entonces, ya podemos deducir el tiempo que se tarda Jaime en producir un reloj:

$$
\phi^{15}=\frac{\text { Un reloj }}{\text { Producción de reloj por hora }}=\frac{1 \text { reloj }}{0.4890227273 \text { reloj } / \text { hora }}=2.044894734 H_{L C}
$$

Entonces, un reloj se producirá en 2.04 horas de trabajo complejo, aproximadamente. Para encontrar la producción de relojes en horas de trabajo simple, denotamos la siguiente ecuación:

Relojes producidos en una $H_{L S}=\frac{\text { Cantidad de relojes equivalentes en trabajo simple }}{\text { Horas de trabajo mensuales }}$ Relojes producidos en una $H_{L S}=\frac{12.5}{176}=0.07102272727$ 
Para observar la cantidad producida por hora utilizamos la expresión anterior, y obtenemos que un trabajador simple requiere 14.08 horas para producir el valor de un reloj; en cambio, el trabajador con una especialización adicional necesita 2.04 horas.

$$
\frac{H_{L S} \text { para producir un reloj }}{H_{L C} \text { para producir un reloj }}=\frac{14.08 \frac{H_{L S}}{\text { reloj }}}{2.044894734 \frac{H_{L C}}{\text { reloj }}}=6.885440001 \frac{H_{L S}}{H_{L C}}
$$

De modo que, una hora de trabajo complejo equivale a 6.89 horas de trabajo simple. Con esta expresión hemos logrado reducir el trabajo complejo a trabajo simple, para poder equiparar los distintos trabajos como unidad de medida. Finalmente, podemos decir que un reloj vale más que una silla porque requiere de una mayor cantidad de tiempo de trabajo socialmente necesario (o bien, más horas de trabajo simple). Debido al grado de complejidad del trabajo, el trabajo de Jaime (ingeniero mecánico) vale aproximadamente 13.5 veces más que el trabajo de Carlos (carpintero).

\section{Capítulo II}

\section{Contrastación empírica de los modelos teóricos para el caso de El Salvador y Estados Unidos}

Para obtener los resultados de la investigación se utilizó el programa STATA, aplicando un análisis de series de tiempo. Adicionalmente, se han empleado datos de El Salvador (como ejemplo de un país subdesarrollado, subordinado y con un papel secundario) y de Estados Unidos (que ilustra la dinámica del modo de producción capitalista en la actualidad). En cada uno de los modelos se estimó la prueba Dickey-Fuller. El resultado de prueba debe ser menor que 0.1 para demostrar que no existe raíz unitaria y que el modelo es correcto.

\subsection{Modelo neoclásico}

Para la corriente neoclásica se calcularon dos ecuaciones. Una proveniente de la concepción más pura de la teoría, y la otra, la "teoría del capital humano". Así, respectivamente:

$$
\Delta(\text { Wreal })=\beta_{0}+\Delta\left(P M_{L}\right) \beta_{1}+\hat{\mu}
$$

Esta ecuación muestra la variación del salario real en función de la variación del producto marginal; $y$

$$
\ln W n=\beta_{0}+\beta_{1} e d u c+\beta_{2} \exp +\beta_{3} \exp ^{2}
$$


Esta ecuación normalmente se presenta con salarios nominales; es decir, incluyendo la inflación. Vamos a calcular esta misma ecuación eliminando el efecto inflacionario para ver el grado explicativo real de la teoría de capital humano.

\subsubsection{Resultados para El Salvador}

Debido al período de la guerra en El Salvador, se tomaron datos desde el año 1990 al 2012 para lograr observar un comportamiento más adecuado de las variables. En la matriz de dispersión de las variables utilizadas, ${ }^{14}$ se puede ver una relación inversa entre los años de educación y el salario real, así como con la experiencia; mientras que una relación directa de estas variables es con el salario nominal. La relación entre el salario real y la productividad es inversa.

\section{Gráfico 1. Matriz de dispersión para las variables neoclásicas. Modelo El Salvador}

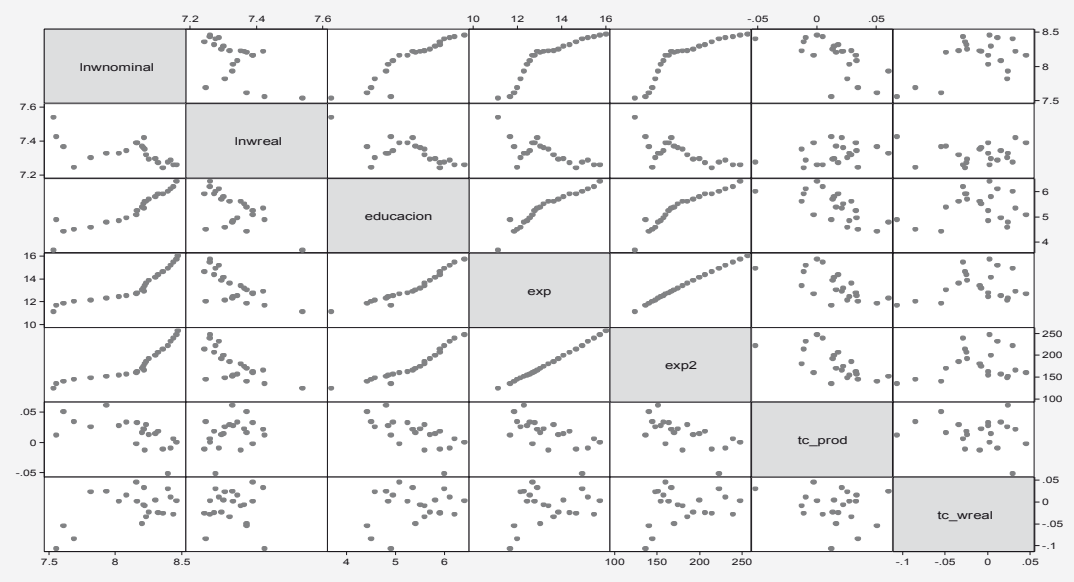

Fuente: Elaboración propia.

\subsubsection{Modelo Neoclásico}

Al estimarse el modelo econométrico relacionando la productividad marginal con los salarios se obtuvo que a medida que se incrementa la productividad en $1 \%$, los salarios reales disminuyen en $0.36 \%$, es decir, sucede todo lo contrario a lo planteado por la teoría neoclásica. El $\mathrm{R}^{2}$ que se obtuvo es de $3.87 \%$, lo que implica que el incremento de la productividad marginal no explica (o lo que explica es despreciable) los cambios en los salarios, lo que también invalida la teoría. En defensa de la teoría neoclásica, existe la posibilidad de que en el mercado de trabajo salvadoreño exista un 
comportamiento monopsónico; es decir, un comportamiento donde la demanda total la ejerce un solo comprador (falla del mercado).

\section{Cuadro 4. Regresión: Salarios reales y productividad. Modelo El Salvador}

\begin{tabular}{r|crc} 
Source & SS & $\mathrm{df}$ & MS \\
\hline Mode1 & .001554522 & 1 & .001554522 \\
Residua1 & .03856566 & 20 & .001928283 \\
\hline Total & .040120182 & 21 & .001910485
\end{tabular}

$\begin{array}{lrr}\text { Number of obs } & \equiv & 22 \\ \mathrm{~F}(1, \quad 20) & =0.81 \\ \text { Prob }>\mathrm{F} & =0.3799 \\ \text { R-squared } & =0.0387 \\ \text { Adj R-squared } & = & -0.0093 \\ \text { Root MSE } & = & .04391\end{array}$

\begin{tabular}{r|rrrrrr}
\hline tcwreal & Coef. & std. Err. & $t$ & $\mathrm{P}>|\mathrm{t}|$ & \multicolumn{2}{c}{ [95\% Conf. Interva]] } \\
\hline tcprod & -.3590746 & .3999187 & -0.90 & 0.380 & -1.19329 & .4751411 \\
-cons & -.0061994 & .0110894 & -0.56 & 0.582 & -.0293314 & .0169326 \\
\hline
\end{tabular}

Fuente: Elaboración propia. ${ }^{15}$

\subsubsection{Modelo del capital humano}

Para estimar el modelo neoclásico del capital humano se utilizaron datos relacionados con la educación y la experiencia. En este caso, la medida de bondad de ajuste o $\mathrm{R}^{2}$ fue de $93.13 \%$; por lo tanto, los resultados son significativos. Por cada año de educación adicional, los salarios nominales se incrementan en $0.076 \%$; y por cada año de experiencia, estos se incrementan en $2.1 \%$, disminuyendo en $0.07 \%$ por cada año de experiencia al cuadrado. Estos rendimientos son muy pequeños, a pesar de que se está tomando en cuenta la inflación. Eliminando el efecto inflacionario podemos obtener tres modelos; el primero, toma en cuenta solo la educación; el segundo, solo la experiencia; el tercero, tanto educación como experiencia.

Cuadro 5. Regresión: Modelo de capital humano con salarios reales. Modelo El Salvador

\begin{tabular}{|c|c|c|c|c|c|c|}
\hline & coef. & Std. Err. & $z$ & $P>|z|$ & [95\% conf. & Interval] \\
\hline $\begin{array}{l}\text { Inwreal } \\
\text { educacio } \\
\text {-con }\end{array}$ & $\begin{array}{r}-.0370839 \\
7.530827\end{array}$ & $\begin{array}{l}0115573 \\
0625254\end{array}$ & $\begin{array}{r}-3.21 \\
120.44\end{array}$ & & $\begin{array}{r}-.0597358 \\
7.40828\end{array}$ & $\begin{array}{l}=.0 \\
7.6\end{array}$ \\
\hline $\begin{array}{r}\text { 21nwrea1 } \\
\exp \\
\operatorname{exp2} \\
\text {-cons }\end{array}$ & $\begin{array}{r}-.1148304 \\
.0035008 \\
8.235883\end{array}$ & $\begin{array}{r}.046 \\
.001 \\
.3\end{array}$ & $\begin{array}{r}-2.46 \\
2.17 \\
24.57\end{array}$ & & $\begin{array}{r}-.2 \\
7 .\end{array}$ & $\begin{array}{r}-.02 \\
.00 \\
8.8\end{array}$ \\
\hline $\begin{array}{r}\text { nwreal } \\
\text { educacion } \\
\text { exp } \\
\text { exp2 } \\
\text { ccons }\end{array}$ & $\begin{array}{r}.0446365 \\
-.2548819 \\
.0077699 \\
9.099052\end{array}$ & $\begin{array}{l}.0170301 \\
.1061986 \\
.0036534 \\
.7074437\end{array}$ & $\begin{array}{r}2.62 \\
-2.40 \\
2.13 \\
12.86\end{array}$ & $\begin{array}{l}0.009 \\
0.016 \\
0.033 \\
0.000\end{array}$ & $\begin{array}{r}.0112582 \\
-.4630273 \\
-0006093 \\
7.712488\end{array}$ & $\begin{array}{r}.0780148 \\
-.0467365 \\
.0149305 \\
10.48562\end{array}$ \\
\hline
\end{tabular}

Endogenous variables: 1nwreal

Exogenous variables: educacion exp exp2

Fuente: Elaboración propia. ${ }^{16}$

52 _ Yusef Ali Bukele Ortez, César Enrique Marroquín Rivas, Juan Carlos Méndez Funes, Edgar Romeo Rodríguez Herrera 
Acá nos enfocaremos en el tercer modelo. La expresión minceriana muestra que a medida que se incrementan los años promedio de educación en una unidad, el salario real se incrementa en $0.04 \%$, mientras que a medida que se incremente la experiencia, este disminuye en $0.25 \%$, aumentando en $0.007 \%$ por cada año de experiencia al cuadrado. Finalmente, la prueba de bondad y ajuste mostró los siguientes resultados: en el primer modelo se obtuvo un $\mathrm{R}^{2}$ de $32.21 \%$; en el segundo modelo, un $\mathrm{R}^{2}$ de $38.94 \%$; mientras que en el tercer modelo se obtuvo un $\mathrm{R}^{2}$ de $45.33 \%$, lo que implica que los modelos explican la realidad de una manera aceptable.

Cuadro 6. Prueba de bondad y ajuste de la regresión: Modelo de capital humano con salarios reales. Modelo El Salvador

Three-stage least-squares regression

\begin{tabular}{lrrrrrr}
\hline Equation & Obs & Parms & RMSE & "R-sq" & chi2 & P \\
\hline 1nwrea1 & 23 & 1 & .0561687 & 0.3221 & 10.30 & 0.0013 \\
27nwrea1 & 23 & 2 & .0533069 & 0.3894 & 14.09 & 0.0009 \\
31nwrea1 & 23 & 3 & .0504428 & 0.4533 & 16.32 & 0.0010 \\
\hline
\end{tabular}

Fuente: Elaboración propia.

\subsubsection{Resultados para Estados Unidos}

Para Estados Unidos se utilizó una serie de datos desde 1963 a 2013 para el modelo neoclásico, y de 1979 a 2013 para el modelo de capital humano. ${ }^{17}$

Gráfico 2. Matriz de dispersión: variables neoclásicas. Modelo Estados Unidos

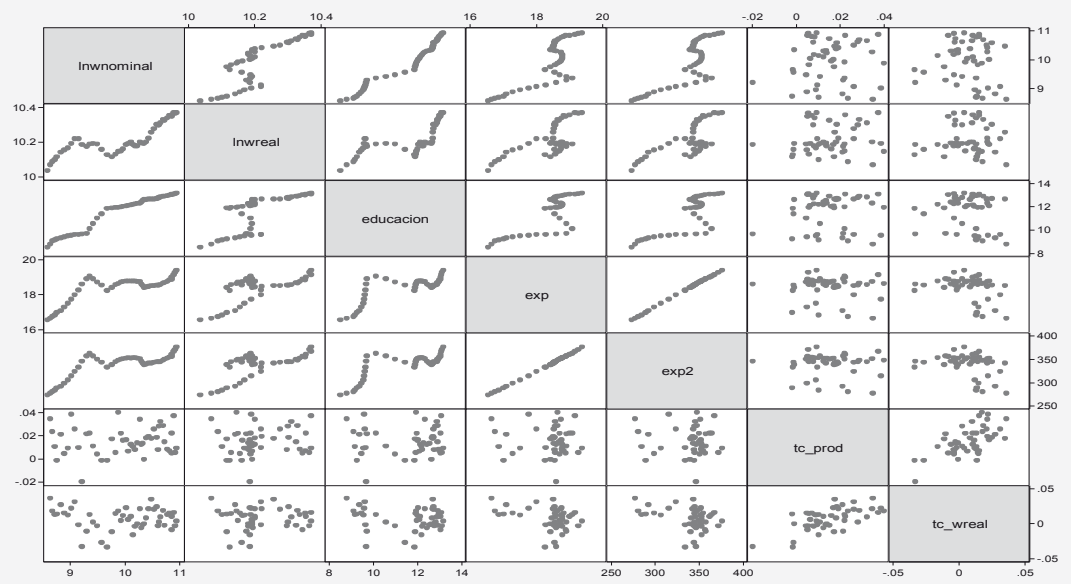

Fuente: Elaboración propia. 
La Matriz de dispersión del modelo neoclásico refleja que hay una relación directa entre el salario real y el nivel de educación, así como con la experiencia, mientras que la experiencia potencial presenta un comportamiento cóncavo. Con respecto a los salarios reales, hay un comportamiento parecido. La relación entre la productividad y el salario real tiende a ser positiva, aunque se denota una nube de puntos un poco dispersa.

\subsubsection{Modelo neoclásico}

La tasa de crecimiento de la productividad marginal es la variable que estima en cuánto varían los salarios reales. Los resultados del modelo neoclásico para Estados Unidos nos indicaron que ante una variación de $1 \%$ en la productividad marginal, los salarios reales anuales se incrementan en $0.82 \%$. Contrario a lo que ocurre en el caso de El Salvador, para Estados Unidos la productividad sí tiene una relación directa con los salarios reales, pero su impacto no es muy significativo, ya que la medida de bondad de ajuste es de 0.3950 .

\section{Cuadro 7. Regresión: entre el salario real y la productividad. Modelo} Estados Unidos

\begin{tabular}{r|crc} 
Source & SS & df & MS \\
\hline $\begin{array}{r}\text { Mode1 } \\
\text { Residua1 }\end{array}$ & .004616481 & 1 & .004616481 \\
\hline Tota1 & .007070823 & 47 & .000150443 \\
\hline Tota87304 & 48 & .000243486
\end{tabular}

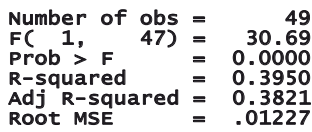

\begin{tabular}{r|rrrrrr}
\hline tc_wrea] & Coef. & std. Err. & $t$ & P $>|t|$ & [95\% Conf. Interva1] \\
\hline tc_prod & .8195318 & .1479437 & 5.54 & 0.000 & .5219076 & 1.117156 \\
_cons & -.0054993 & .0028557 & -1.93 & 0.060 & -.0112443 & .0002457
\end{tabular}

Fuente: Elaboración propia. ${ }^{18}$

\subsubsection{Modelo del capital humano}

Por cada año de educación adicional, los salarios nominales crecen en $0.7546 \%$; mientras que cada año de experiencia incrementa los salarios nominales en un $15.5033 \%$, un aumento muy significativo; y por cada año de experiencia al cuadrado, los salarios disminuyen en $0.4064 \%$, lo que significa que los incrementos de cada año de experiencia son cada vez menores. El $\mathrm{R}^{2}$ es significativo (97.96\%). Estimando el modelo de capital humano sin el efecto inflacionario, obtenemos 3 modelos: 
Cuadro 8. Regresión: Modelo de capital humano con salarios reales. Modelo Estados Unidos

\begin{tabular}{|c|c|c|c|c|c|c|}
\hline & coef. & Std. Err. & $z$ & $P>|z|$ & [95\% conf. & Interval] \\
\hline $\begin{array}{r}\text { 7nwreal } \\
\text { educacion } \\
\text {-cons }\end{array}$ & $\begin{array}{r}1559558 \\
8.291996\end{array}$ & $\begin{array}{l}.0117443 \\
.1469031\end{array}$ & $\begin{array}{l}13.28 \\
56.45\end{array}$ & $\begin{array}{l}0.000 \\
0.000\end{array}$ & $\begin{array}{r}.1329373 \\
8.004072\end{array}$ & $\begin{array}{r}.1789743 \\
8.579921\end{array}$ \\
\hline $\begin{array}{r}27 \text { nwrea1 } \\
\text { exp } \\
\text { _cons }\end{array}$ & $\begin{array}{r}1717896 \\
7.029366\end{array}$ & $\begin{array}{l}.0479082 \\
.8958482\end{array}$ & $\begin{array}{l}3.59 \\
7.85\end{array}$ & $\begin{array}{l}0.000 \\
0.000\end{array}$ & $\begin{array}{r}.0778914 \\
5.273536\end{array}$ & $\begin{array}{r}.2656879 \\
8.785196\end{array}$ \\
\hline $\begin{array}{r}31 \text { nwreal } \\
\text { educacion } \\
\text { exp } \\
\text { exp2 } \\
\text { _cons }\end{array}$ & $\begin{array}{r}.1391523 \\
.3766329 \\
-.0092473 \\
4.693277\end{array}$ & $\begin{array}{l}.0098591 \\
.8827821 \\
.023461 \\
8.312988\end{array}$ & $\begin{array}{r}14.11 \\
0.43 \\
-0.39 \\
0.56\end{array}$ & $\begin{array}{l}0.000 \\
0.670 \\
0.693 \\
0.572\end{array}$ & $\begin{array}{r}1198288 \\
-1.353588 \\
-.05523 \\
-11.59988\end{array}$ & $\begin{array}{r}1584758 \\
2.106854 \\
.0367354 \\
20.98643\end{array}$ \\
\hline $\begin{array}{l}\text { dogenous } \\
\text { ogenous } v\end{array}$ & $\begin{array}{l}\text { es: } \\
\text { s: }\end{array}$ & ion & & & & \\
\hline
\end{tabular}

Fuente: Elaboración propia.

Cuadro 9. Prueba de bondad y ajuste de la regresión: Modelo de capital humano con salarios reales. Modelo Estados Unidos

Three-stage least-squares regression

\begin{tabular}{lrrrrrr}
\hline Equation & Obs & Parms & RMSE & "R-sq" & chi2 & P \\
\hline 1nwrea1 & 34 & 1 & .0318139 & 0.8488 & 176.34 & 0.0000 \\
27nwrea1 & 34 & 1 & .0674392 & 0.3207 & 12.86 & 0.0003 \\
31nwrea1 & 34 & 3 & .0306644 & 0.8596 & 224.62 & 0.0000 \\
\hline
\end{tabular}

Fuente: Elaboración propia.

Enfocándonos en el tercer modelo, podemos ver que por cada año adicional de educación, los salarios reales se incrementan en $0.1391 \%$; por cada año de experiencia, estos se incrementan en $0.3766 \%$; y por cada año de experiencia al cuadrado, estos disminuyen en $0.0092 \%$. El $\mathrm{R}^{2}$ es de 85.96, que lo hace mucho más significativo que el modelo neoclásico puro. $^{19}$

\subsection{Modelo marxiano}

Desde la teoría marxiana planteamos 3 ecuaciones..$^{20}$ La primera se realizó con variables instrumentales, y presenta la relación entre el salario real $(\mathrm{Wr})$ y el valor de la fuerza de trabajo (VFT) en función de los años de educación (), y la productividad () en función de la CVFT, y la composición orgánica de capital (n), de esta forma:

$$
W r=\beta_{0}+\beta_{1} \operatorname{VFT}\left(\bar{x}_{t}\right)+\beta_{2} \pi(C V F T, n)+\hat{u}_{t}
$$


La segunda ecuación, también empleando variables instrumentales, presenta el logaritmo natural del

$$
\ln V F T=\beta_{0}-\beta_{1} \ln \pi(C V F T, \ln n)+\hat{u}_{t}
$$

La tercera ecuación presenta la relación entre el logaritmo natural de la productividad y el logaritmo

$$
\ln \pi=\beta_{0}+\beta_{1} \ln C V F T+\beta_{2} n+\beta_{3} \operatorname{lntasapv}+\hat{u}_{t}
$$

\subsubsection{Resultados para El Salvador}

Para desarrollar una medición empírica desde la teoría marxiana en El Salvador, se utilizó una serie de datos desde 1990 hasta 2013.

\section{Gráfico 3. Matriz de dispersión de variables marxianas. Modelo El} Salvador

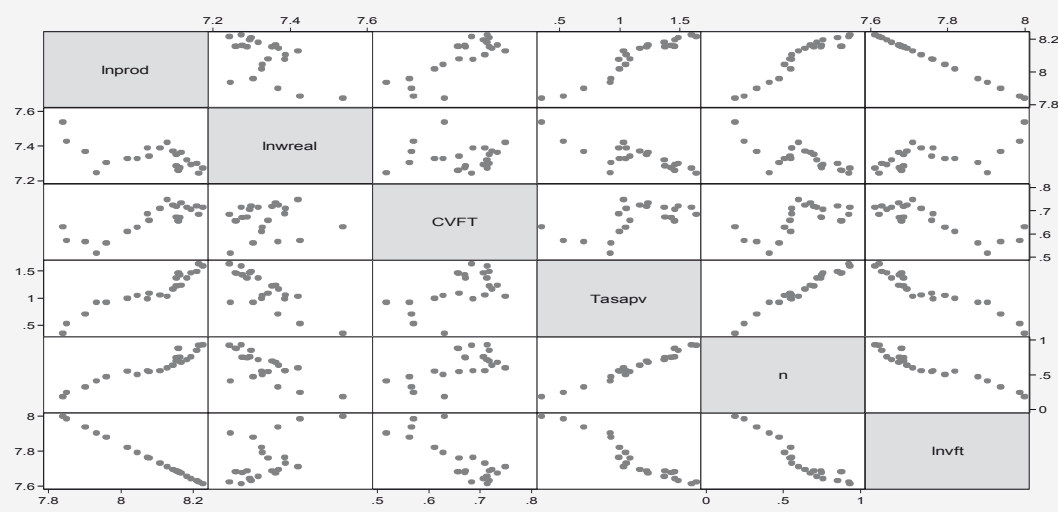

Fuente: Elaboración propia.

En el Gráfico 3 se observa la relación entre las variables, evidenciándose una relación directa entre el salario real y la CVFT, así como una relación inversa de la CVFT con la tasa de plusvalor y la composición orgánica de capital. 
Cuadro 10. Regresión: Salario real, valor de la fuerza de trabajo, educación promedio, productividad, cobertura del valor de la fuerza de trabajo y la composición orgánica de capital. Modelo El Salvador

Instrumental variables (2SLS) regression

\begin{tabular}{|c|c|c|c|c|c|c|}
\hline Source & ss & $d f$ & MS & & \multirow{3}{*}{$\begin{array}{l}\text { Number of obs } \\
\text { FC } 2 \text {, } 11) \\
\text { Prob }>\text { F } \\
\text { R-squared } \\
\text { Adj R-squared } \\
\text { Root MSE }\end{array}$} & \multirow{3}{*}{$\begin{array}{lr}= & 14 \\
= & 86.05 \\
= & 0.0000 \\
= & 0.9427 \\
= & 0.9322 \\
= & 21.826\end{array}$} \\
\hline $\begin{array}{r}\text { Mode } 7 \\
\text { Residua } 7\end{array}$ & $\begin{array}{l}86152.9699 \\
5240.21135\end{array}$ & $\begin{array}{rr}2 & 430 \\
11 & 47 \\
\end{array}$ & $\begin{array}{r}43076.4849 \\
476.38285 \\
\end{array}$ & & & \\
\hline Tota1 & 91393.1812 & 7030 & 7030.24471 & & & \\
\hline wreal & coef. & std. Err. & $t$ & $P>|t|$ & [95\% conf. & Interva1] \\
\hline$v f t$ & .2670752 & .1049779 & 2.54 & 0.027 & .0360205 & .4981299 \\
\hline $\begin{array}{r}\text { productivi }{ }_{\text {L9. }} \\
\text {. }\end{array}$ & -.2096392 & .0211587 & -9.91 & 0.000 & -.2562091 & -.1630693 \\
\hline _cons & 1577.902 & 263.6373 & 5.99 & 0.000 & 997.6403 & 2158.164 \\
\hline $\begin{array}{l}\text { Instrumented: } \\
\text { Instruments: }\end{array}$ & \multicolumn{3}{|c|}{$\begin{array}{l}\text { vft L9:productividad } \\
\text { educacion cvft n }\end{array}$} & & & \\
\hline
\end{tabular}

Fuente: Elaboración propia. ${ }^{21}$

Esta regresión nos muestra que a medida que aumenta en un dólar el VFT en función de la educación promedio, los salarios reales se incrementan en US\$0.27; mientras que ante un incremento de la productividad en función de la CVFT y de la composición orgánica de capital, los salarios reales disminuyen en US\$0.21 por cada dólar. Esto muestra el efecto positivo que tiene el aumento de la escolaridad promedio en el VFT, y este en la cantidad de bienes que la masa de trabajadores puede adquirir. Mientras que por el lado de la productividad, se muestra que a medida que se incrementa, los salarios reales se van deteriorando progresivamente.

En una segunda ecuación, se relaciona el VFT y el nivel de productividad para observar el mecanismo de plusvalía relativa. Se obtienen los siguientes resultados:

Cuadro 11. Regresión: Valor de la fuerza de trabajo, productividad, cobertura del valor de la fuerza de trabajo y la composición orgánica de capital. Modelo El Salvador

\begin{tabular}{|c|c|c|c|c|c|c|c|}
\hline \multicolumn{8}{|l|}{ rumental } \\
\hline source & ss & df & & MS & & \multirow{3}{*}{$\begin{array}{l}\text { Number of obs } \\
\text { FC } 1 \text {, } 20 \text { ) } \\
\text { Prob }>\text { F } \\
\text { R-squared } \\
\text { Adj R-squared } \\
\text { Root MSE }\end{array}$} & \multirow{3}{*}{$\begin{array}{l}604.32 \\
0.0000 \\
0.9678 \\
0.9662 \\
.01968\end{array}$} \\
\hline $\begin{array}{r}\text { Model } \\
\text { Residual }\end{array}$ & $\begin{array}{l}.232695938 \\
.007747817\end{array}$ & 20 & \multicolumn{2}{|c|}{$\begin{array}{l}.232695938 \\
.000387391 \\
\end{array}$} & & & \\
\hline Total & .240443755 & 21 & \multicolumn{2}{|c|}{.011449703} & & & \\
\hline $7 n v f t$ & coef. & std. & Err. & $t$ & $P>|t|$ & [95\% conf. & Interval] \\
\hline $\begin{array}{c}7 \text { nprod } \\
\text { L1. }\end{array}$ & -.9047621 & .0368 & 045 & -24.58 & 0.000 & -.9815351 & -.8279892 \\
\hline -cons & 15.05299 & .2976 & 221 & 50.58 & 0.000 & 14.43216 & 15.67382 \\
\hline $\begin{array}{l}\text { nstrumented } \\
\text { nstruments: }\end{array}$ & $\begin{array}{l}\text { L. Tnprod } \\
\text { incevt n }\end{array}$ & & & & & & \\
\hline
\end{tabular}

Fuente: Elaboración propia. ${ }^{22}$ 
A medida que se incrementa la productividad, en función de la CVFT y la n, en un punto porcentual por trabajador, el VFT decrece en $0.91 \%$. Esto nos muestra la relación inversa existente entre ambas variables, expresándose el mecanismo de plusvalía relativa. El R $R^{2}$ es de $96.78 \%$, es decir que el modelo es muy significativo.

En el Cuadro 12 se muestra que a medida se incrementa la CVFT en un punto porcentual, la productividad por trabajador se incrementa en $0.47 \%$. Mientras que un cambio en la composición orgánica de capital en una unidad, incrementa la productividad media anual en $0.1394 \%$; y a medida que se incrementa la tasa de plusvalía (explotación) en un punto porcentual, la productividad aumenta en $0.1597 \%$. Esto muestra que los incrementos en la tasa de explotación aumentan la productividad pero en menor proporción que el incremento que genera en la productividad una mayor CVFT.

Cuadro 12. Regresión: entre la productividad, tasa de plusvalía, cobertura del valor de la fuerza de trabajo y la composición orgánica de capital. Modelo El Salvador

\begin{tabular}{r|rrr} 
Source & Ss & df & \multicolumn{1}{c}{ MS } \\
\hline $\begin{array}{r}\text { Mode1 } \\
\text { Residua1 }\end{array}$ & .304778279 & 3 & .10159276 \\
\hline Tota1 & .301035492 & 19 & .0000545 \\
\hline
\end{tabular}

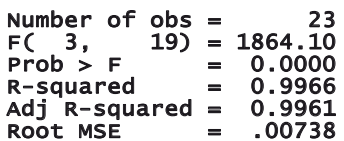

\begin{tabular}{|c|c|c|c|c|c|c|}
\hline Inprod & coef. & std. Err. & $t$ & $P>|t|$ & [95\% conf. & Interva1] \\
\hline $\begin{array}{r}\text { 1ncvft } \\
\text { 1ntasapv } \\
n \\
\text { econs }\end{array}$ & $\begin{array}{r}470723 \\
.1597041 \\
.1394211 \\
5.288799\end{array}$ & $\begin{array}{l}.0207306 \\
.0124628 \\
.0248801 \\
.1015459\end{array}$ & $\begin{array}{r}22.71 \\
12.81 \\
5.60 \\
52.08\end{array}$ & $\begin{array}{l}0.000 \\
0.000 \\
0.000 \\
0.000\end{array}$ & $\begin{array}{r}.4273333 \\
.1336191 \\
.0873464 \\
5.076261\end{array}$ & $\begin{array}{r}5141127 \\
.185789 \\
.1914957 \\
5.501337\end{array}$ \\
\hline
\end{tabular}

Fuente: Elaboración propia ${ }^{23}$.

\subsubsection{Resultados para Estados Unidos}

Para desarrollar una medición empírica de la teoría marxiana en Estados Unidos, como país desarrollado, se tomaron datos desde 1963 hasta 2013. 
Gráfico 4. Matriz de dispersión de las variables marxianas. Modelo Estados Unidos

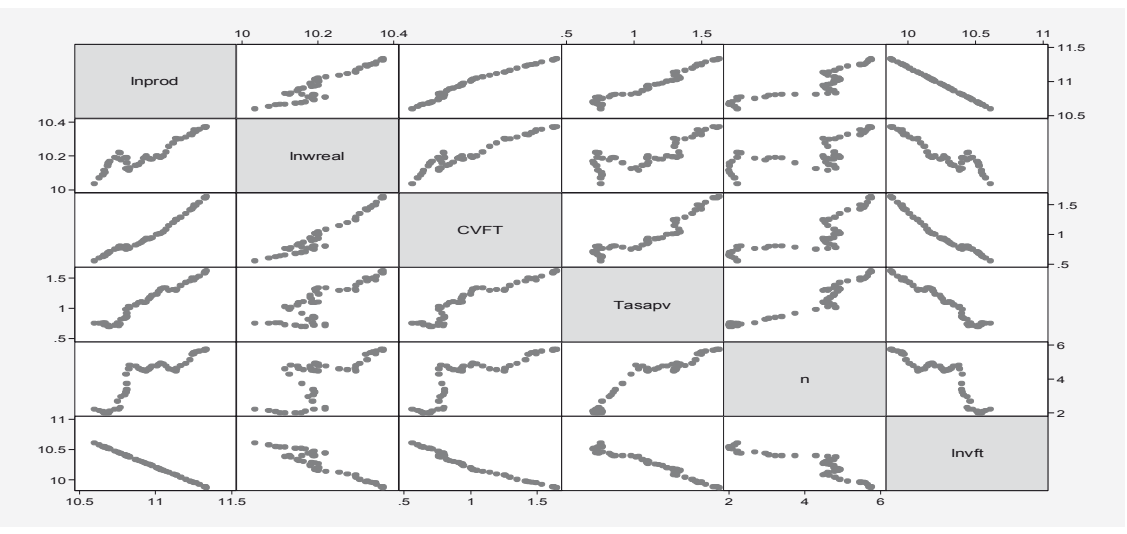

Fuente: Elaboración propia.

Esta matriz de dispersión muestra que a medida que se incrementa la productividad, disminuye el salario real; y a medida que se incrementa el salario real, la productividad aumenta. Se puede ver también una relación directa entre la CVFT y la productividad, y una relación inversa con el VFT. Existe además, una relación directa entre la composición orgánica de capital y la productividad, así como con la tasa de plusvalor.

En el Cuadro 13 se observa que a medida que aumenta en un dólar el VFT en función de la educación promedio, los salarios reales anuales se incrementan en US\$ 0.44 , mientras que un incremento de la productividad en función de la CVFT y de la composición orgánica de capital, hace que los salarios reales aumenten en US\$ 0.38 anuales. Esto muestra el efecto positivo que el aumento de la escolaridad promedio tiene sobre el VFT, y este en la cantidad de bienes que los trabajadores pueden adquirir. La medida de bondad de ajuste de la relación entre las variables es del $86.88 \%$, es significativa. 
Cuadro 13. Regresión: Salario real, valor de la fuerza de trabajo, educación promedio, productividad, cobertura del valor de la fuerza de trabajo y composición orgánica de capital. Modelo Estados Unidos

\begin{tabular}{r|rrr} 
Source & \multicolumn{1}{|c}{ SS } & df & MS \\
\hline $\begin{array}{r}\text { Mode1 } \\
\text { Residua1 }\end{array}$ & 361049356 & 2 & 120524678 \\
\hline Tota1 & 277436300 & 49 & 5661965.31
\end{tabular}

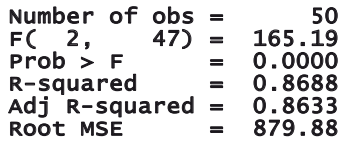

\begin{tabular}{r|rcccrr}
\hline wrea1 & Coef. & std. Err. & $t$ & P>|t| & [95\% Conf. Interva1] \\
\hline vft & .4355856 & .1220719 & 3.57 & 0.001 & .1900086 & .6811626 \\
productivi d & .3793145 & .0579695 & 6.54 & 0.000 & -2626949 & $\mathbf{4} 959341$ \\
_cons & -7506.658 & 6918.573 & -1.09 & 0.283 & -21425.03 & 6411.716 \\
\hline
\end{tabular}

Instrumented: vft productividad

Instruments: educacion cvft $n$

Fuente: Elaboración propia. ${ }^{24}$

Veamos el segundo modelo econométrico para Estados Unidos. A medida que se incrementa la productividad, en función de la CVFT y la $n$, en un punto porcentual, el VFT decrece en $1 \%$. Esto nos muestra la relación inversa existente entre ambas variables, expresándose el mecanismo de plusvalía relativa.

Cuadro 14. Regresión: Valor de la fuerza de trabajo, productividad, cobertura del valor de la fuerza de trabajo y la composición orgánica de capital. Modelo Estados Unidos

\begin{tabular}{r|crc} 
Source & SS & df & MS \\
\hline $\begin{array}{r}\text { Mode1 } \\
\text { Residua1 }\end{array}$ & 2.10555231 & 3 & .701850769 \\
\hline Tota1 & 2.11214239 & 48 & .044002967
\end{tabular}

$\begin{array}{llr}\text { Number of obs } & =r \\ \mathrm{FC} 3, & 49 \\ \text { Prob }>\text { F } & = & 4792.54 \\ \text { R-squared } & =0.0000 \\ \text { Adj R-squared } & = & 0.9969 \\ \text { Root MSE } & 0.9967 \\ & = & .0121\end{array}$

\begin{tabular}{r|rrrrrr}
\hline L.Inprod & Coef. & Std. Err. & $t$ & P $>|t|$ & [95\% Conf. Interva1] \\
\hline 1ntasapv & .2004008 & .036296 & 5.52 & 0.000 & .1272969 & .2735048 \\
1ncvft & .5293339 & .0173008 & 30.60 & 0.000 & .4944883 & .5641795 \\
$n$ & .0049883 & .0057404 & 0.87 & 0.389 & -.0065735 & .0165501 \\
_cons & 10.92588 & .0209769 & 520.85 & 0.000 & 10.88363 & 10.96813 \\
\hline
\end{tabular}

Fuente: Elaboración propia. ${ }^{25}$

Con la tercera ecuación se obtuvieron los siguientes resultados:

En el Cuadro 15 se muestra que a medida que se incrementa la CVFT en un punto porcentual, la productividad por trabajador se incrementa en $0.529 \%$. Mientras que un cambio en la $\mathrm{n}$ hace que la productividad media se incremente en $0.0049 \%$; por otra parte, a medida que se incremente la tasa de plusvalía en un punto porcentual, la productividad 
se incrementará en $0.20 \%$. Esto muestra que los incrementos en la tasa de explotación aumentan la productividad, pero a menor proporción que el incremento que genera la CVFT sobre la productividad. El $R^{2}$ es de $99.69 \%$, extremadamente significativo.

Cuadro 15. Regresión: entre la productividad, tasa de plusvalía, cobertura del valor de la fuerza de trabajo y la composición orgánica de capital.

Modelo Estados Unidos

\begin{tabular}{r|crc} 
Source & SS & df & MS \\
\hline $\begin{array}{r}\text { Mode1 } \\
\text { Residua1 }\end{array}$ & 2.10555231 & 3 & .701850769 \\
\hline Tota1 & 2.11214239 & 48 & .044002967
\end{tabular}

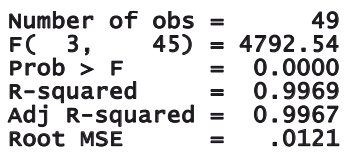

\begin{tabular}{r|rrrrrr}
\hline L. Inprod & Coef. & Std. Err. & $t$ & $\mathrm{P}>|\mathrm{t}|$ & [95\% Conf. Interva1] \\
\hline Intasapv & .2004008 & .036296 & 5.52 & 0.000 & .1272969 & .2735048 \\
1ncvft & .5293339 & .0173008 & 30.60 & 0.000 & .4944883 & .5641795 \\
$\mathrm{n}$ & .0049883 & .0057404 & 0.87 & 0.389 & -.0065735 & .0165501 \\
_cons & 10.92588 & .0209769 & 520.85 & 0.000 & 10.88363 & 10.96813 \\
\hline
\end{tabular}

Fuente: Elaboración propia. ${ }^{26}$

\subsection{Resultados de los modelos econométricos para El Salvador y Estados Unidos}

Cuadro 16. Matriz de resultados para El Salvador

\begin{tabular}{|c|c|c|c|c|c|c|c|c|c|c|}
\hline Variables & \multirow{2}{*}{\multicolumn{4}{|c|}{$\begin{array}{c}\text { MODELO NEOCLÁSICO } \\
\text { Salarios reales }\end{array}$}} & \multicolumn{6}{|c|}{ MODELO MARXIANO } \\
\hline Dependientes & & & & & \multicolumn{2}{|c|}{ Salarios reales } & \multirow{2}{*}{$\begin{array}{c}\text { Ln VFT } \\
\text { Ln prod } \\
(\mathrm{n}, \mathrm{ln} \\
\text { CVFT)* }\end{array}$} & \multicolumn{3}{|c|}{ In productividad } \\
\hline Independientes & Pmg & Educ & Exp & Exp2 & $\operatorname{VFT}(x)^{*}$ & $\begin{array}{l}\text { Prod (n, } \\
\text { CVFT)* }\end{array}$ & & $\begin{array}{c}\operatorname{Ln} \\
\text { CVFT* }^{*}\end{array}$ & LnTasapv* & $\mathrm{n}^{*}$ \\
\hline Signo Teórico & $(+)$ & $(+)$ & $(+)$ & $(+)$ & $(+)$ & $\begin{array}{l}\text { (Depende } \\
\text { del grado } \\
\text { de CVFT) }\end{array}$ & $(-)$ & $(+)$ & $\begin{array}{l}\text { (Depende } \\
\text { del grado } \\
\text { de CVFT) }\end{array}$ & $(+)$ \\
\hline Signo Resultante & $(-)$ & $(+)$ & $(-)$ & $(+)$ & $(+)$ & $(-)$ & $(-)$ & $(+)$ & $(+)$ & $(t)$ \\
\hline Coeficiente & -0.359 & 0.0445 & -0.255 & 0.0078 & 0.267 & -0.209 & -1.005 & 0.471 & 0.16 & 0.139 \\
\hline Estadístico t & -0.9 & $z=2.62$ & $z=-2.40$ & $z=2.13$ & 2.54 & -9.91 & -122.38 & 22.71 & 12.81 & 5.6 \\
\hline Prob. T & 0.364 & $\mathrm{pz}=0.009$ & $p z=0.016$ & $\mathrm{pz}=0.033$ & 0.027 & 0 & 0 & 0 & 0 & 0 \\
\hline Estadístico F & 0.81 & \multicolumn{3}{|c|}{ chi-cuadrado $=16.32$} & \multicolumn{2}{|r|}{86.05} & $14,976.32$ & \multicolumn{3}{|c|}{$1,864.00$} \\
\hline Prob. F & 0.38 & \multicolumn{3}{|c|}{ pchi-cuadrado $=0.0010$} & \multirow{2}{*}{\multicolumn{2}{|c|}{$\begin{array}{r}0 \\
9427 \%\end{array}$}} & 0 & \multicolumn{3}{|r|}{ then } \\
\hline$R^{2}$ & $3.87 \%$ & & & $45.33 \%$ & & & $99.69 \%$ & & & $9.66 \%$ \\
\hline
\end{tabular}

Fuente: Elaboración Propia. *Se asume el principio ceteris paribus. Cifras aproximadas. 


\begin{tabular}{|c|c|c|c|c|c|c|c|c|c|c|}
\hline \multicolumn{11}{|c|}{ Cuadro 17. Matriz de resultados para Estados Unidos } \\
\hline Variables & \multirow{2}{*}{\multicolumn{4}{|c|}{$\begin{array}{c}\text { MODELO NEOCLÁSICO } \\
\text { Salarios reales }\end{array}$}} & \multicolumn{6}{|c|}{ MODELO MARXIANO } \\
\hline Dependientes & & & & & \multicolumn{2}{|c|}{ Salarios reales } & \multirow{2}{*}{$\begin{array}{c}\text { Ln VFT } \\
\text { Ln prod } \\
(\mathrm{n}, \ln \\
\text { CVFT) }{ }^{*}\end{array}$} & \multicolumn{3}{|c|}{ Ln productividad } \\
\hline Independientes & $\mathrm{Pmg}_{\mathrm{L}}$ & Educ & Exp & Exp2 & $\operatorname{VFT}(\mathbf{x})^{*}$ & $\begin{array}{l}\text { Prod (n, } \\
\text { CVFT)* }\end{array}$ & & $\begin{array}{l}\ln \\
\text { CVFT* }\end{array}$ & LnTasapv* & $\mathrm{n}^{*}$ \\
\hline Signo Teórico & $(+)$ & $(+)$ & $(+)$ & $(+)$ & $(+)$ & $\begin{array}{c}\text { (Depende } \\
\text { del grado } \\
\text { de CVFT) }\end{array}$ & $(-)$ & $(+)$ & $\begin{array}{l}\text { (Depende } \\
\text { del grado } \\
\text { de CVFT) }\end{array}$ & $(+)$ \\
\hline \begin{tabular}{|l|} 
Signo \\
Resultante
\end{tabular} & $(-)$ & $(+)$ & $(+)$ & $(-)$ & $(+)$ & $(+)$ & $(-)$ & $(+)$ & $(+)$ & $(+)$ \\
\hline Coeficiente & 0.819 & 0.139 & 0.377 & -0.009 & 0.436 & 0.379 & -1.006 & 0.529 & 0.2 & 0.005 \\
\hline Estadístico t & 5.54 & $\mathrm{z}=14.11$ & $z=0.43$ & $z=-0.39$ & 3.57 & 6.54 & -122.38 & 30.6 & 5.52 & 0.87 \\
\hline Prob. T & 0 & $\mathrm{pz}=0.000$ & $\mathrm{pz}=0.670$ & $p z=0.693$ & 0.001 & 0 & 0 & 0 & 0 & 0.001 \\
\hline Estadístico F & 30.69 & & hi-cuadrad & $0=224.62$ & & 165.19 & $14,976.32$ & & & 792.54 \\
\hline Prob. F & 0 & & & 0 & & 0 & 0 & & & 0 \\
\hline $\mathrm{R}^{2}$ & $39.50 \%$ & & & $85.96 \%$ & & $86.88 \%$ & $99.69 \%$ & & & $9.69 \%$ \\
\hline
\end{tabular}

Fuente: Elaboración propia. *Se asume el principio ceteris paribus.

En la matriz de resultados de ambos países se demuestra, en tanto su explicación y complejidad, mediante la utilización de modelos econométricos, y de acuerdo a los parámetros planteados por cada escuela, la teoría marxiana es la que explica de mejor manera la realidad.

\section{Capítulo III}

\section{Implicaciones sociales y de política económica}

\subsection{Políticas económicas}

En los años 90 se desarrollaron una serie de medidas de políticas económicas en América Latina, basadas en lo que se conoció como el "Consenso de Washington" (CW). Las políticas planteadas en este "consenso" fueron apoyadas por el Fondo Monetario Internacional
(FMI), por el Banco Mundial (BM) y por la Tesorería de los Estados Unidos, entre otras entidades. A ello se deben los cuestionamientos que surgen al denominarle "consenso", ya que las medidas no fueron escritas por los países en general. Calderón (2007) enuncia las principales políticas económicas descritas en este documento:

El CW aseveraba que la mayoría de las instituciones de investigación y de las agencias involucradas en la formulación de políticas públicas para el desarrollo concuerdan 
en los siguientes principios esenciales para el desarrollo: (1) disciplina fiscal; (2) reorganización del gasto público para canalizarlo hacia la atención médica básica, la educación primaria y la infraestructura; (3) reforma fiscal para reducir las tasas marginales de impuestos y aumentar así la recaudación total; (4) liberalizar las tasas de intereses; (5) sostener un tipo de cambio "competitivo"; (6) eliminar las restricciones cuantitativas al comercio y convertirlas en aranceles que luego serían reducidos paulatinamente hasta llegar a un arancel efectivo promedio de entre 10 y 20\%; (7) liberalizar el flujo de inversión extranjera directa; (8) privatizar las empresas estatales; (9) eliminar las barreras al ingreso y salida del mercado, reduciendo trabas legales innecesarias y (10) fortalecer los derechos de propiedad privada.

Estados Unidos por su parte, en la década de los 90, se adapta a la globalización económica mundial mediante el uso de las altas tecnologías, creciendo a través de la centralización de las gestiones empresariales y diversificando sus actividades productivas.

\subsubsection{Políticas educativas en El Salvador y Estados Unidos}

Luego de la firma de los acuerdo de paz (1992), el gobierno de El Salvador buscó apoyo financiero y técnico en organismos internacionales como el Banco Mundial (BM), el Banco Interamericano de Desarrollo (BID), el Sistema de las Naciones Unidas, la Unión Europea, y países aliados (España, México, Japón, entre otros). El gobierno de Alfredo Cristiani, insertado en la lógica neoliberal, comenzó a realizar transferencias de funciones y competencias del Ministerio de Educación (MINED) para reducir el Estado; asimismo focalizó el gasto público educativo según el Plan de Desarrollo Económico y Social (Mi Plan, 1989-1994) a los "grupos de extrema pobreza". En el gobierno de Calderón Sol (1994-1999), uno de los objetivos principales era el de hacer un país de "zonas francas", por lo que se incentivó el sector maquilero; pero ya que este no requiere de mano de obra cualificada, se eliminó un año de bachillerato. En el gobierno de Francisco Flores (1999-2004) se continuó con el paquete neoliberal, privatizando más recursos estratégicos y dolarizando la economía (2001). Mientras que en el período de Elías Antonio Saca (2004-2009) se incluye el bachillerato gratuito, y en el gobierno de Mauricio Funes (20092014) se implementa la gratuidad de los uniformes, zapatos y útiles escolares. 
En el caso de Estados Unidos, luego de promover el Consenso de Washington alrededor del mundo, promovió políticas para incrementar su desarrollo tecnológico, y por lo tanto, empezó a requerir una fuerza de trabajo más cualificada. Con este fin, se implementan una serie de medidas con la meta de llegar a ser los primeros en el mundo, en términos de logros educativos, especialmente en Ciencias y Matemática. Una de estas medidas fue el programa Goals 2000, que entre sus características fundamentales se encontraba la aplicación de estándares para verificar logros académicos, el perfeccionamiento docente y el impulso de la participación ciudadana (U.S. Department of Education, 1996, p. 8). Sin embargo, el creciente costo de la educación superior en los últimos años ha obstaculizado dicha meta. Ronald G. Ehrenberg, administrador del sistema de universidades estatales de Nueva York y director del Instituto Cornell de Investigación de Educación Superior, (como lo cita Chomsky, 2012), adjudica esto a un cambio cultural: "Ha habido un cambio de la creencia de que como nación nos beneficiamos de la educación superior a la creencia de que la gente que recibe educación es la más beneficiada y que, por tanto, debería pagar el costo". Aun así, entre 1963 y 2012, los años promedio de educación se han incrementado significativamente, especialmente en Estados Unidos.

\section{Gráfico 5. Años promedio de educación en El Salvador y Estados Unidos 1963-2012}

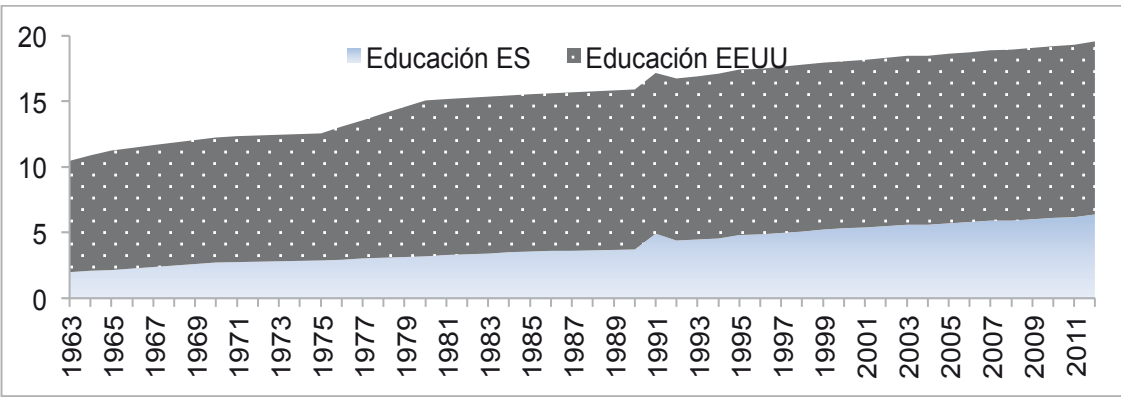

Elaboración propia con base en datos de la EHPM y Barro and Lee.

\subsubsection{Políticas salariales e} implicaciones en el desarrollo social de la fuerza de trabajo

Entre las medidas planteadas por Alfredo Cristiani se encontraba la flexibilidad laboral, apoyado en estudios de FUSADES (Fundación Salvadoreña para el Desarrollo Económico y Social) y sugerencias de la ANEP (Asociación Nacional de la Empresa Privada). 
Estos planteaban que los salarios mínimos generaban desconfianza para la inversión, ya que se encontrarían por encima del nivel de "equilibrio" (que jamás se menciona cuál es) y por lo tanto, se debe de eliminar para que el mercado funcione y se logre una mayor "competitividad".

Raúl Moreno (2004) señala las principales consecuencias de la flexibilización laboral:

Inestabilidad laboral, precarización de las condiciones de trabajo, generalización de contratación por aprendizaje, imposición de contratos temporales, pérdida de prestaciones históricamente conseguidas, negativa a reconocer pagos por nocturnidad, horas extras y días feriados, congelamiento de facto de los salarios mínimos, congelamiento de la revalorización de las pensiones, discriminación en la contratación por embarazo o historial sindical, irrespeto del derecho de libertad de organización, despidos de trabajadores sindicalizados y organizados del sector público, despidos por la supresión arbitraria de plazas, quiebre de la organización sindical, negativa de las autoridades a dar personalidad jurídica a sindicatos del sector público y tolerancia del Ministerio de Trabajo ante violaciones de los derechos laborales. (pp. 31-32)

En los períodos de Calderón Sol, Francisco Flores, y Antonio Saca, se continúa con las mismas políticas de flexibilización laboral apoyado en los Programas de Ajuste Estructural (PAE) y Estabilidad Económica (PEE).

Desde la implementación del modelo neoliberal, se articularon tres factores esenciales para incrementar la tasa de ganancia del capital internacional: la flexibilización laboral, ya sea legal o de facto; la liberalización comercial y aduanera (globalización comercial); y la desregularización financiera (globalización financiera).
En los últimos años los salarios se han "estancado", y lo que se ha incrementado aceleradamente ha sido la ganancia apropiada por los capitalistas. En los gobiernos de los años 90, la flexibilización laboral ha obedecido a dos necesidades primordiales. En primer lugar, la necesidad de las empresas de hacer uso de una mano de obra que pueda ser utilizada con versatilidad, para que estas puedan hacer frente a los retos que les impone la globalización; y en segundo lugar, la necesidad de reducir al mínimo las tasas de desempleo a fin de lograr una estabilidad en el nivel de empleo. 
A pesar de las políticas implementadas, los salarios mínimos de El Salvador y de Estados Unidos han sido totalmente insuficientes para cubrir las necesidades básicas de los habitantes de cada país. Es decir, las aplicaciones de la teoría económica dominante (neoliberal), han sido ineficaces para mejorar las condiciones de vida de los trabajadores.

\section{Gráfico 6. Cobertura del valor de la fuerza de trabajo en El Salvador y Estados Unidos 1990-2012}

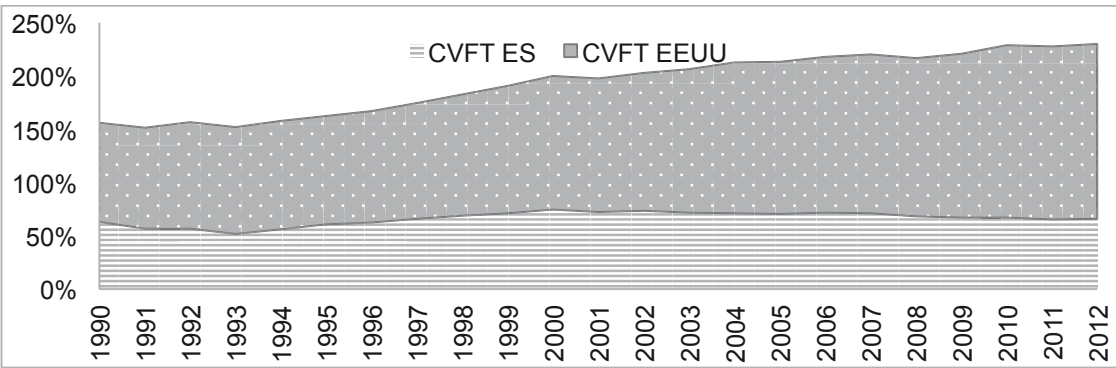

Fuente: Elaboración propia con base en datos del ISSS, BCR y BEA.

En este gráfico podemos observar que en El Salvador existe una descobertura progresiva del VFT, y a la vez, una disminución del nivel de productividad de la sociedad. En cambio, en Estados Unidos, existe una cobertura más que plena del VFT en términos promedio, y al mismo tiempo, existe una mayor eficiencia productiva dentro de la sociedad.

\subsubsection{Implicaciones de la insuficiente cobertura del valor de la fuerza de trabajo en El Salvador}

Entre los gastos sociales en $\mathrm{El}$ Salvador se encuentran los gastos en educación, salud y las transferencias gubernamentales (salario indirecto). Estos gastos son ínfimos en comparación de otros gastos que realiza el gobierno como porcentaje del PIB (entre ellos la deuda pública). Como se observa, los gastos sociales en el año de 1998 constituían tan solo el $7.41 \%$ del PIB, mientras que en el año 2010 eran del $11.14 \%$. 
Gráfico 7. Gastos sociales en El Salvador como porcentaje del PIB 1998-2010

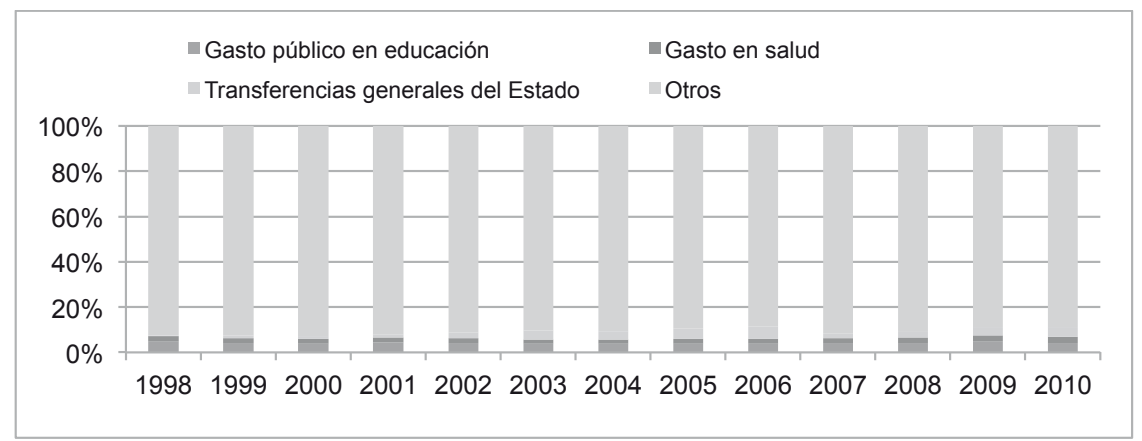

Fuente: Elaboración propia con base en datos del PNUD y Ministerio de Hacienda.

Debido a la insuficiente cobertura del VFT en El Salvador y la deficiente inversión social del Estado, los trabajadores han buscado formas para autorreproducir el valor de su fuerza de trabajo. Es por ello que existe una gran cantidad de trabajadores en el sector informal. En el año 2012, estos ascendieron a $50.37 \%$ del total de personas ocupadas del sector urbano, según la EHPM (1990-2012). Otro de los mecanismos es la migración. Una de las consecuencias de esto último son las remesas, que implican una considerable contribución a la economía de El Salvador. En 1991, las remesas representaban el $14.19 \%$ del PIB, y en 2007 , el $18.38 \%$; para luego decrecer al $16.30 \%$ en 2013 , como resultado de la crisis. No exportamos gente para traer ingresos, exportamos riqueza productiva para traer "sobras". Actualmente, un migrante promedio produce un valor de $\$ 85,284.65$ anuales, una cantidad mucho mayor a lo recibido como remesas; por lo tanto, es más lo que se "pierde" cuando la fuerza de trabajo migra, que lo que relativamente se "gana".

\subsection{Medidas e implicaciones de acción social en El Salvador y Estados Unidos}

Las medidas de acción social en El Salvador se pueden realizar mediante movimientos sociales, los cuales inciden haciendo presión como "actores políticos colectivos", incidiendo sobre los diferentes problemas económicos, políticos y sociales del país. El principal movimiento social que puede incidir sobre los salarios, la productividad y el trabajo cualificado, es el sindicato. A lo largo de la historia ha existido una fuerte presión negativa ante las iniciativas sindicales, o cualquier acción social de la población en El Salvador, ya que ello genera "discordia" según la clase 
política y empresarial salvadoreña. La legislación actual permite que los sindicatos solo posean 35 miembros dentro de ella, lo que limita enormemente su capacidad de influencia. Actualmente existen 627 sindicatos inscritos, 455 están activos y el 172 son acéfalos. Según el Ministerio de Trabajo, los sindicatos inscritos para junio 2014 se dividen en: gremio (77), empresa (173), industria (91), trabajadores independientes (192) y sector público (94). Algunos problemas de los sindicatos en El Salvador han sido, según Arriola (1995): "Atomización, falta de liderazgo, mala capacitación sindical, orientación preferente a la capacitación y no a la organización, falta de autonomía financiera y el inmediatismo en la acción sindical" (pp. 63-66).

En Estados Unidos han existido a lo largo de la historia luchas sindicales fuertes, como el combate entre trabajadores por la estipulación de 8 horas de trabajo (44 horas semanales), las huelgas dirigidas en 1886 que, entre otras actividades, estimularon el incremento salarial y la disminución de horas de trabajo; asimismo, ayudaron a disminuir las desigualdades entre mujeres y hombres. A pesar de esto, el movimiento sindical ha perdido fuerza en los últimos años, debido a la implementación del modelo económico neoliberal en el país. Actualmente están prohibidas las huelgas en conjunto, además, si un sector va a la huelga no puede ser secundado, ya que es ilegal. Asimismo, están prohibidos los paros repentinos por cualquier queja por parte de los trabajadores, ya que según el gobierno de los Estados Unidos, esto genera una inestabilidad laboral. Los problemas fundamentales en la formación y desarrollo de los sindicatos son: si un sector se encuentra en huelga no puede ser secundado; los trabajadores asalariados se encuentran empleados por contrato de trabajo, generalmente de cinco años; las huelgas se pueden hacer solo en períodos de nuevos contratos; el despido de los trabajadores es libre y la indemnización depende del tiempo de cada contrato; y la preferencia de negociaciones individuales sobre las colectivas.

\subsection{Implicaciones sociales y de política económica en el desarrollo social y de la fuerza de trabajo en El Salvador y Estados Unidos}

Estados Unidos tiene un progreso tecnológico mucho mayor que El Salvador, esto se ve reflejado en el índice de composición orgánica de capital de ambos países. A medida en que se incrementa la composición orgánica de capital, se incrementa el grado de mecanización o automatización de una economía, y los incrementos en esta implican aumentos de la productividad. 
Gráfico 8. Composición orgánica de capital EL SALVADOR y ESTADOS

UNIDOS 1990-2012

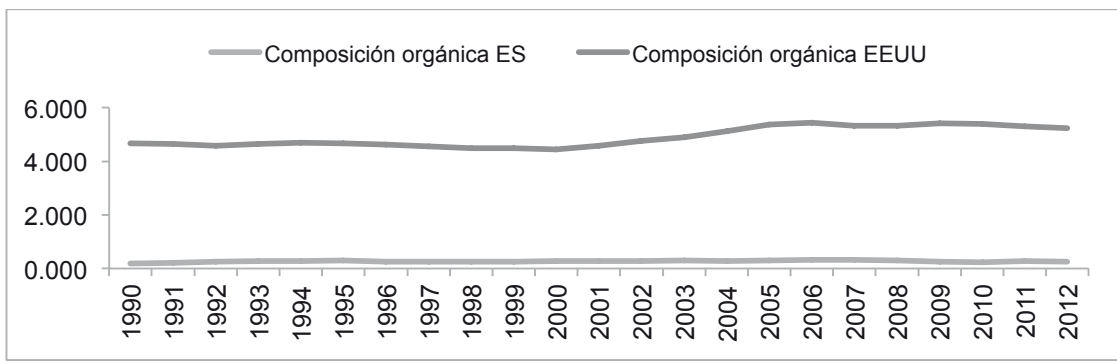

Fuente: Elaboración propia a partir de datos del ISSS, EPWT, BLS y BEA.

A medida que se incrementa la acumulación de capital (suponiendo constante la composición orgánica), se incrementa la demanda de trabajo; por lo tanto, se incrementan los salarios de la clase trabajadora. Pero el sistema capitalista no funciona de esta manera, ya que el capital solo puede sobrevivir por medio del desarrollo constante de las fuerzas productivas. El Estado ha facilitado y defendido las condiciones para que la acumulación de capital se incremente constantemente.

En Estados Unidos se observa un incremento relativo de la tasa de acumulación de capital, y descensos marcados en los períodos de crisis del petróleo en los años 70, la crisis de la deuda en los años 80, la crisis "puntocom" en el año 2000 y recientemente, la crisis económica del 2009. Con respecto a la tendencia de la tasa de acumulación en El Salvador, se observa un declive en los años de 1967-68. Luego se observa una disminución debido al conflicto armado en los años 80, así como en 1996 y en los años 2000 y 2007-2009 con las crisis financieras de los Estados Unidos. En 1996 se empieza a observar el agotamiento del reciente modelo de crecimiento económico fundamentado en el sector terciario maquilero implementado en $\mathrm{El}$ Salvador desde los años 90 


\section{Gráfico 9. Acumulación de capital en Estados Unidos 1963-2013. Año base 2009}

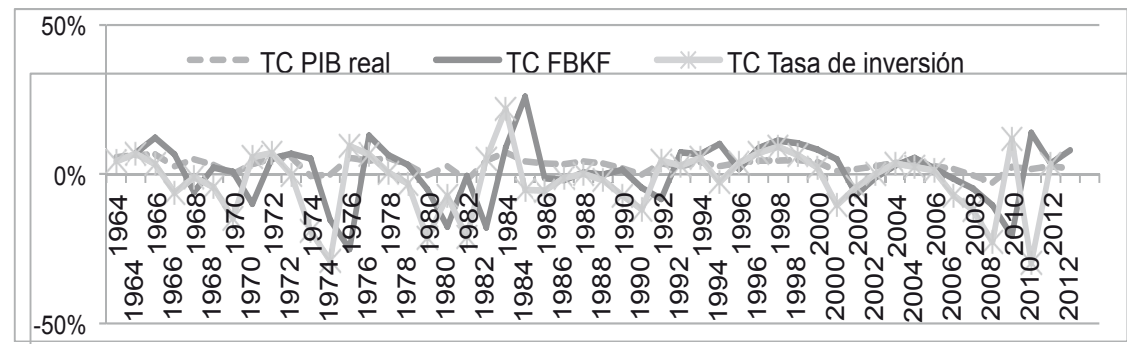

Fuente: Elaboración propia a partir de datos del WDI y BEA.

\section{Gráfico 10. Acumulación de capital en El Salvador 1966-2013. Año base 2009}

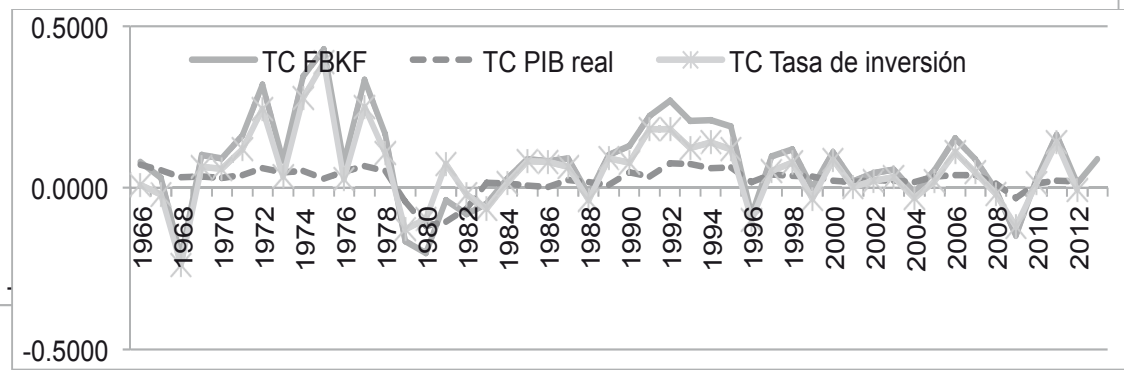

Fuente: Elaboración propia a partir de datos del WDI.

Normalmente se piensa que como los trabajadores en Estados Unidos reciben una mayor retribución en salarios y logran cubrir sus medios de vida, son menos explotados que los trabajadores de un país del "submundo capitalista", donde los salarios no cubren el VFT. Pero sucede lo contrario; en el caso salvadoreño y estadounidense, a pesar que un trabajador en Estados Unidos gana lo suficiente para cubrir sus costos de vida, es mucho más explotado que un trabajador salvadoreño, ya que el empresario capitalista estadounidense se apropia de una mayor cantidad de plusvalía. Es decir, los empresarios estadounidenses ganan muchísimo más que los empresarios salvadoreños, y el pago a la fuerza de trabajo es menos que proporcional a sus ganancias, esto a comparación con el pago que realizan los empresarios salvadoreños. La tasa de ganancia ${ }^{27}$ muestra la realidad fenoménica en la que se presenta la plusvalía como el fruto de todo el capital, esta presenta la proporción en la que se valoriza todo el capital variable. 
Gráfico 11. Tasa de plusvalía en El Salvador y Estados Unidos 1990-2013

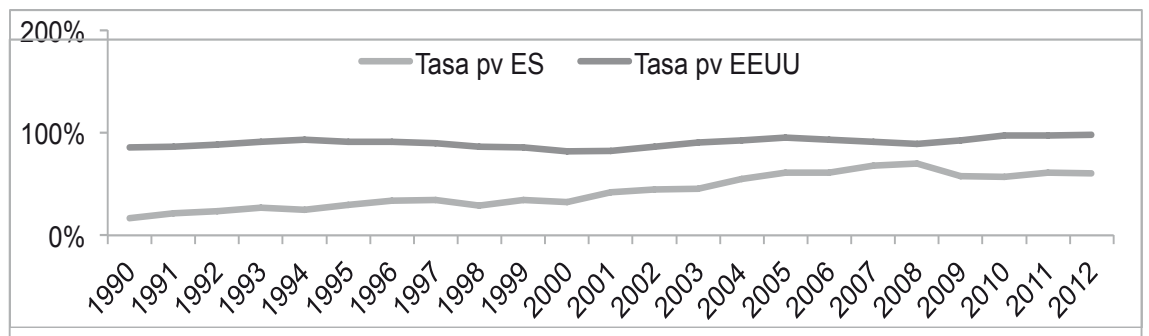

Fuente: Elaboración propia a partir de datos del BEA, EPWT, ISSS y BCR.

En los siguientes Gráficos (12 y 13), se observa claramente la caída de la tasa de ganancia en los Estados Unidos y en El Salvador con la crisis de 1974-75, con la crisis de 1980-82, la recesión del año 2001 y con la última crisis y depresión en 2007-2009. Esto debido a los incrementos, en largos períodos, de la composición orgánica de capital superior a los de la tasa de plusvalía, lo cual se expresa en una caída de la tasa general de ganancia. Esta caída tendencial de la tasa de ganancia termina afectando la masa de ganancia, que se estanca en los períodos de crisis y luego se recupera paulatinamente. En la tasa de ganancia en El Salvador se presentan características similares, sufriendo su mayor caída entre los años de 1994, 1996-1998 y 2008-2009.

\section{Gráfico 12. Tasa de ganancia Estados Unidos 1963-2012}

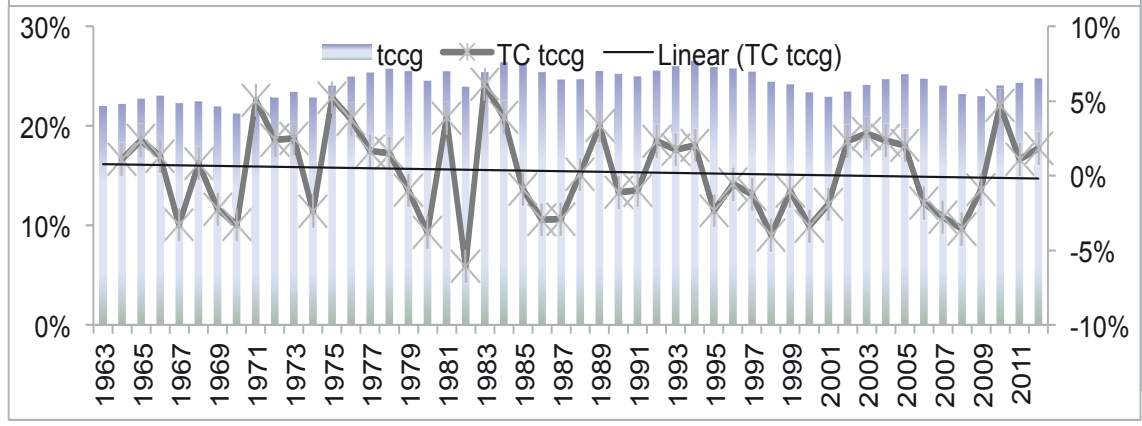

Fuente: Elaboración propia a partir de datos del BEA Y EPWT. 


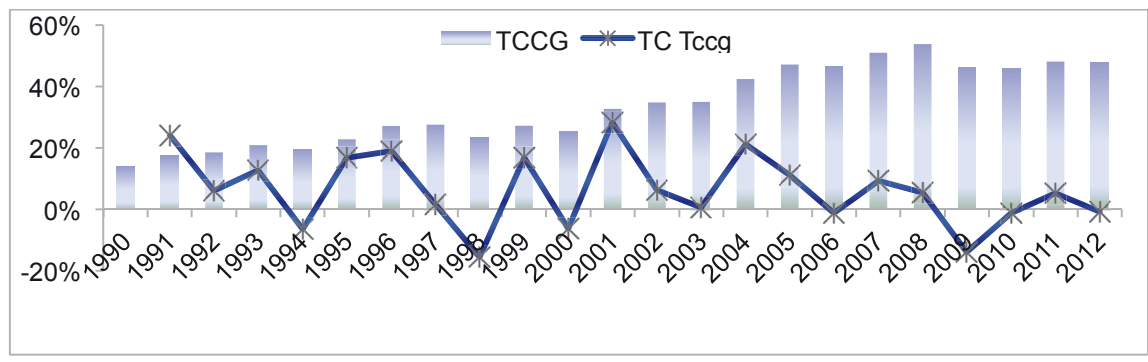

Fuente: Elaboración propia a partir de datos del ISSS, BCR y EPWT.

\subsection{Recomendaciones de acción social y de política económica}

Eliminar la flexibilización laboral que atenta contra la vida del trabajador al deteriorar las condiciones de vida pagándoles por debajo del VFT (en El Salvador) e incrementando la jornada de trabajo o intensidad de la misma, entre otras medidas. Además, se debe de fortalecer el sindicato apoyado en instituciones.

I. Implementación gradual y heterogéneo de un salario mínimo que logre retribuir a la fuerza de trabajo por el valor creado, pero esto implicaría una desaparición del sistema capitalista; por lo tanto, al menos se debe de plantear remunerarla por su valor (especialmente en el caso salvadoreño), o al menos al nivel de la inflación en el corto plazo. Para ello se debe de aumentar la inversión social, no como "capital", sino como ser humano, y única fuente creadora del valor y de la riqueza de la sociedad.
II. Se debe procurar la inversión local sobre la extranjera, hay aproximadamente US\$ 20,496.6 millones potencialmente invertibles en El Salvador y US\$ 6,774.94 billones en Estados Unidos por parte de los empresarios capitalistas locales, con esto nos podemos salir de la lógica del subdesarrollo que espera inversión extranjera directa, y empezar a invertir en sectores que potencien el desarrollo de las personas y del país (no solo sectores rentables).

III. Todas las medidas de política económica deben considerar la igualdad entre hombres y mujeres, así como medidas de desarrollo social encaminadas a la restitución del medio ambiente con leyes fuertes que castiguen los abusos laborales.

IV. El Salvador debe incrementar la productividad vía tecnología (como lo ha hecho Estados Unidos) diversificando el aparato productivo y no 
compensar el rezago tecnológico por vía de la depresión del salario real de la clase trabajadora, ya que este mengua las capacidades productivas de la fuerza de trabajo y de la sociedad.

V. Cambiar el modelo económico neoliberal, adoptado por el Consenso de Washington como modelo de re-acumulación primaria de capital, por un modelo económico más inclusivo. Finalmente, se deben de propiciar las condiciones para cambiar la estructura económica (infraestructura) y la estructura política, jurídica e ideológica (superestructura), para obtener un sistema distinto al capitalismo, encaminado hacia un sistema económico solidario.

\section{Conclusiones y reflexiones}

Productividad: De acuerdo a los resultados obtenidos, la idea neoclásica de que un aumento en la productividad de los trabajadores generará aumentos en sus salarios es falsa. En los dos países estudiados, la productividad ha aumentado, pero los salarios de los trabajadores han disminuido (El Salvador) o prácticamente se han estancado (Estados Unidos). Los empresarios se han apropiado de este aumento en la productividad de los trabajadores; en su mayoría, como el caso de Estados Unidos; o en su totalidad, como el caso de El Salvador (en este último, sería de su totalidad y algo más, ya que la productividad ha aumentado en un $40 \%$ respecto a 1990 , pero los salarios reales, lejos de haber aumentado, han disminuido en un $30 \%$ ). Con el tiempo los trabajadores se están volviendo más productivos pero siguen trabajando las mismas horas y recibiendo la misma o una menor compensación.
Si quisiéramos ser "equitativos", la lógica nos indicaría de que si la productividad aumenta, los salarios tendrían que aumentar o la jornada de trabajo tendría que disminuir (o una combinación de esto). Como hemos visto, esto no ha sido el caso en estos dos países, principalmente en el caso de El Salvador, donde no solo no ha habido una compensación, sino que incluso ha existido una considerable descompensación. Alguien podría decir que estos resultados están equivocados, ya que en la práctica si alguien se vuelve más productivo que sus compañeros se le pagará más, debido a que produce más que los demás. Esto puede ser cierto si tomamos la productividad individualmente; si tomamos a la productividad como una productividad relativa (qué tanto se produce respecto a los demás) y no como una productividad absoluta (qué tanto se produce en sí). Se puede explicar esto bajo una perspectiva 
neoclásica mediante la oferta y la demanda: si mágicamente toda la población se vuelve un $10 \%$ más productiva, bajo el mecanismo de la oferta y la demanda, los salarios no tendrían por qué subir. De acuerdo con la teoría marxiana, esto también tiene su explicación, ya que un aumento en la productividad promedio disminuye el valor de la fuerza de trabajo y por consiguiente los salarios. Pero si un trabajador individual aumenta su productividad al doble, independientemente de los demás, el valor de su fuerza de trabajo aumentaría, ya sea por un mayor desgaste o por una complejización de su trabajo (Montoya, 2000). Esta es una de las razones por las que la sociedad es cada vez más inequitativa. Esta especie de brecha de productividad, donde los más ricos se apropian cada vez más de lo que produce el resto, genera una creciente inequidad con considerables efectos negativos, no solo morales o éticos, sino también graves efectos económicos y sociales. El aumento de la productividad está lejos de ser algo negativo; lo negativo es tan solo uno de los efectos de algo indudablemente positivo. Lo que hay que hacer es modificar este efecto de la brecha de la productividad para que el aumento en la productividad genere un mayor bienestar para la sociedad. Esto se puede hacer mediante una política salarial que tome en cuenta no solo el aumento en los precios (como supuestamente se hace en la actualidad), sino también el aumento en la productividad de los trabajadores; o mediante una política impositiva altamente progresiva donde los impuestos recaudados sean utilizados en servicios públicos como una forma de retribución a los trabajadores por su creciente contribución a la producción.

Educación: El caso de la educación es muy similar al de la productividad. La perspectiva neoclásica nos dice que a mayor educación, mayores salarios. De acuerdo a nuestros resultados, vemos que es cierto que hay un incremento en los salarios cuando hay un incremento en los años de educación promedio de los trabajadores; el problema es que ese incremento es prácticamente nulo $(0.0446 \%$ por cada año de educación en el caso de El Salvador, y $0.1391 \%$ en el caso de Estados Unidos). La explicación de ello es muy similar a la explicación de la productividad. Lo que hace que haya un incremento en los salarios de un trabajador no es su educación por sí sola, sino que su educación respecto a la de los demás trabajadores.

A pesar del indudable incremento en la productividad generado por el aumento en los años de educación de la población trabajadora, el incremento en los salarios -debido a este aumento educacional- ha sido prácticamente inexistente. Si a esto le añadimos el incremento en los costos de la 
educación (particularmente en el caso de la educación superior en Estados Unidos), tenemos una situación muy delicada, ya que el desincentivo generado terminará afectando gravemente a la ya precaria situación de la clase trabajadora, y en el mediano y largo plazo, también a la situación del resto de la sociedad. Observando estos resultados, está claro que los indudables beneficios que generan una mayor educación y una mayor productividad han sido absorbidos casi en su totalidad por los empresarios de ambos países, una situación claramente insostenible y que explica parcialmente la creciente desigualdad de ingresos en el mundo.

Tasa de explotación: A pesar de que en los Estados Unidos hay una cobertura plena del VFT (con los datos utilizados hay incluso una sobre-cobertura) y que en $\mathrm{El}$ Salvador hay una descobertura, la tasa de explotación en Estados Unidos es mayor que la tasa de explotación en El Salvador. Es decir, a pesar de que hay una sobreexplotación de los trabajadores en El Salvador, y en los Estados Unidos no la hay, la explotación es mayor en este último. Este aparentemente contradictorio resultado se explica mediante la enorme diferencia entre los niveles de productividad de ambos países.

Cobertura del valor de la fuerza de trabajo: $\mathrm{Al}$ incrementar la cobertura del valor de la fuerza de trabajo (CVFT), hay un aumento sustancial en la productividad (por cada incremento de un punto porcentual en la CVFT, la productividad crece $0.47 \%$ en El Salvador y $0.53 \%$ en Estados Unidos). Es decir, El Salvador podría incrementar su PIB en al menos un $16.1 \%$ o en US\$ $3,842,168,400$ tan solo incrementando los salarios medios en US\$204.91 (lo necesario para lograr una cobertura plena: pasándolos de US\$ 393.21 a US\$ 598.12). Este incremento de casi cuatro mil millones de dólares en el PIB es tan solo el ocasionado por el aumento en la productividad de los trabajadores; no se están tomando en cuenta otros efectos, como los generados por la ampliación del mercado interno o el considerable número de beneficios generados por una mayor equidad del ingreso. Todo esto se puede lograr mediante una pequeña redistribución del ingreso; algo que curiosamente ha sido lo opuesto de lo recomendado por organismos internacionales, como el FMI y un sinfín de analistas económicos locales con sus ideas de flexibilidad laboral y desregulación de la economía, entre otras ideas similarmente perniciosas.

\section{Insuficiente cobertura del valor} de la fuerza de trabajo en EI Salvador: A pesar de la histórica insuficiencia en la cobertura del valor de la fuerza de trabajo en El Salvador, su clase trabajadora no ha desaparecido; es más, lejos de 
eso, esta ha aumentado a lo largo del tiempo (la población total ha pasado de 5,480,000 personas en 1995 a 6,297,394 personas en 2012, mientras que la población ocupada ha pasado de 2,135,911 personas a $2,708,794$ personas en este mismo período de tiempo según datos estimados del $B M)$. ¿A qué se debe esta aparente contradicción? A pesar de la marcada descobertura del VFT en El Salvador, los trabajadores salvadoreños han logrado sobrevivir y reproducirse ya que han recurrido a otros mecanismos como el comercio informal, la producción agrícola de subsistencia, la migración y el envío de remesas. A lo largo de la historia, la clase dominante en El Salvador (en su gran mayoría) ha fomentado estos mecanismos, ya que estos les han permitido, en una especie de visión miope y cortoplacista, ganancias extraordinarias generadas por la sobreexplotación de los trabajadores. Algunos de estos mecanismos, a pesar de que han mantenido a la población trabajadora (y al país) con vida a lo largo del tiempo, han generado efectos estructuralmente negativos para todo el país. En el caso de la migración y el envío de remesas, a pesar de que El Salvador recibió casi US\$ 4,000 millones (más del $15 \%$ del PIB) en 2013, este tuvo que exportar a su población más emprendedora y productiva para hacerlo, de este modo se convirtió al país gradualmente más dependiente de los Estados Unidos (el principal destino de los migrantes).

Inversión: También es necesario que parte del excedente económico se reinvierta en el país, ya que existen US\$ 20,496.6 millones potencialmente invertibles como plusvalía en El Salvador. De esta manera se podría reducir la brecha del sector informal y del desempleo. En el caso Estadounidense, existen aproximadamente US $\$$ 6,774.94 billones potencialmente invertibles en el país como plusvalía, lo que podría ser reinvertido en el país y con ello reducir la brecha del desempleo que, según el Banco Mundial, en el año 2012 llegó a ser del $8.10 \%$. Las desigualdades económicas deben de eliminarse paulatinamente vía distribución del ingreso a los más pobres de ambos países. 


\section{Referencias}

- Arriola, J. (1995). Diagnóstico económico del marco de relaciones laborales. San Salvador: Centro de Estudios del trabajo (CENTRA).

- Becker, G., Murphy, K. \& Tamura, R. (1990). "Human capital, Fertility, and Economic Growth". NBER working paper \# 3414. National Bureau of Economic Research. Cambridge.

- Calderon, G (2007, 20 de octubre). El consenso de Washington explicado. Elsalvador.com. Recuperado de http://archivo.elsalvador.com/ mwedh/nota/nota_opinion.asp?idCat=6342\&idArt=1775531

- Chomsky, N. (08 de abril de 2012). "El ataque a la educación pública". Cuba Debate. Recuperado de http://www.cubadebate.cu/ opinion/2012/04/08/noam-chomsky-el-ataque-a-la-educacion-publica/\#. U8k3H5R5M3k.

- Código de Trabajo de la República de El Salvador. Cap. II, art. 161. (2014). San Salvador.

- Gill, L. (2002). Fundamentos y límites del capitalismo. Traducción de Xabier Arrizabalo Montoro. Madrid, España: Editorial Trotta.

- Marx, C. (1980). El Capital. México D.F.: Allende editores.

- MIPLAN, 1989. Plan de Desarrollo Económico y Social del Gobierno de El Salvador 1989-1994. San Salvador, El Salvador.

- Mincer, J. (1974). Schooling, Experience, and Earnings. New York: National Bureau of Economic Research y Columbia University Press.

- Montesino, M. (2007). Importancia del valor de la fuerza de trabajo y de la racionalidad reproductiva para la gestión del desarrollo (Tesis de postgrado). Universidad Autónoma de Honduras, Tegucigalpa.

- Montoya, A. (2000). Economía crítica. San Salvador: Editores críticos.

- Moreno, R. (2004). La globalización neoliberal en El Salvador y sus implicaciones. Barcelona: Fundación Mon-3

- Rosdolsky, R. (2004). Génesis y estructura de El Capital de Marx. México D.F.: Editorial Siglo XXI.

- U.S. Department of Education (30 de abril de 1996). Goals 2000: Increasing student achievement through state and local initiatives. Office of Educational research and Improvement, Educational Resources Information Center (ERIC). Estados Unidos.

- Fuentes Estadísticas 
- Banco Central de Reserva de El Salvador, BCR. (21 de mayo de 2014). Recuperado de http://www.bcr.gob.sv

- Barro and Lee. (21 de mayo de 2014). Educational Attainment, dataset. Recuperado de http://www.barrolee.com

- Bureau of Economic Analysis, BEA. (18 de mayo de 2014). Recuperado de http://www.bea.gov/

- Bureau of Labor Stastics, BLS (24 de enero de 2013). Union Members Summary. Recuperado de http://www.bls.gov/news.release/union2.nr0. htm [último acceso, 21 de julio de 2014].

- Comisión Económica para América Latina, CEPAL. (19 de mayo de 2014). Recuperado de http://websie.eclac.cl/infest/ajax/cepalstat.asp

- Dirección General de Estadísticas y Censos, DIGESTYC. (19 de mayo de 2014). Recuperado de http://www.digestyc.com

- Encuesta de Hogares de Propósitos Múltiples, EHPM (1990-2012). El Salvador.

- Extended Penn World Tables, EPWT. (24 de mayo de 2014) Recuperado de https://sites.google.com/a/newschool.edu/duncan-foley-homepage/ home/EPWT

- Gobierno de El Salvador. (1990-2013). Anuario estadístico del ISSS. San Salvador.

- IMILA. (01 de julio de 2014). Datos estadísticos de la CELADE. Recuperado de http://www.cepal.org/celade/migracion/imila/

- Programa de las Naciones Unidas para el Desarrollo en El Salvador. PNUD El Salvador. (03 de junio de 2014). Recuperado de http://www. pnud.org.sv

- World Development Indicators, WDI. (23 de mayo de 2014). Recuperado de http://data.worldbank.org/ 
Notas

1 Principalmente tierra, trabajo y

10 Sillas por hora $=$ Producción mensual de sillas / Horas de trabajo mensual

capital, y últimamente se le agrega la tecnología.

2 Los diferentes grados de cualificación del trabajador.

3 Donde Inw: Logaritmo natural del Ingreso por trabajador; $\beta_{0}$ : Salario de una persona sin educación, ni experiencia; $\beta_{1}$ : Parámetro de rentabilidad de la educación; $\beta_{2}$ : Parámetro de rentabilidad de la experiencia; $\beta_{3}$ : Parámetro de rentabilidad de la experiencia potencial; educ: Años de educación; exp: Años de experiencia; $\exp ^{2}$ : Experiencia potencial.

4 Las 176 horas mensuales son equivalentes a 44 horas semanales, y 8 horas por jornada laboral de lunes a viernes, con excepción del día sábado que sólo se trabajan 4 horas.

5 La canasta de mercado es calculada a partir de la Encuesta de Hogares de Propósitos Múltiples (EHPM), que incorpora aproximadamente 238 bienes, y es la canasta de bienes con la cual se calcula el Índice de Precios al Consumidor (IPC).

$6 \quad$ El énfasis es nuestro.

7 Grado en que se valoriza el capital variable, $P V=p v / v$; sea PV la tasa de plusvalía o tasa de explotación, $p v$ la plusvalía y $v$ es el capital variable. Expresado así: $\frac{P I B \text { real }- \text { RA real }}{\text { RA real }}$.

8 El valor de la fuerza de trabajo es de 822.53 U.M., multiplicado por la tasa de explotación del sector comercial (111.44\%), la plusvalía apropiada sería de 916.63 U.M.

9 Es el resultado de las sillas producidas por su precio (10 U.M.) ya descontado el valor nuevo creado.

11 Dias de trabajo necesarios $=$ Tiempo de trabajo necesario/Horas por dias de trabajo.

12 Como al mes se trabajan 176 horas, la diferencia entre el tiempo de trabajo necesario para reproducir los medios de vida del trabajador simple considerado como capital variable $(V)$, con las horas de trabajo mensuales de un trabajador en El Salvador es el tiempo de trabajo excedente.

13 Los gastos sociales se calcularon con datos del PNUD en El Salvador, tomados del Ministerio de Hacienda, mientras que los gastos privados se calcularon de acuerdo a la ponderación de la canasta de mercado calculada por la DYGESTIC, y al salario se le sumó el valor de la fuerza de trabajo que posee un trabajador simple en el año 2012.

14 Recuérdese que mensualmente se producen 250 sillas, y que 20 sillas equivalen a 1 reloj. Por ello dividimos las 250 sillas entre las 20 que se producen por cada reloj, así obtenemos 12.5 relojes mensuales en tiempo socialmente necesario de trabajo simple.

$15 \phi=$ Tiempo para producir una unidad de la mercancía.

16 Los datos se tomaron de las siguientes fuentes estadísticas: El PIB real base 1990, se encontró en el Banco Central de Reserva de El Salvador (BCR); la remuneración de los asalariados y el número de trabajadores asalariados, se tomaron de los anuarios estadísticos de varios años del Instituto del Seguro Social Salvadoreño (ISSS); La educación promedio, se tomó de varias Encuesta de Hogares de Propósitos 
Múltiples (EHPM); el nivel de experiencia, se calculó según datos disponibles en el Banco Mundial (WDI) y mediante cálculos propios; para estimar el nivel de productividad se utilizó el PIB real, dividido entre el número de ocupados dentro de la población económicamente activa. El número de ocupados se tomó de la EHPM.

17 El modelo muestra una relación log-log por la medición en tasas de crecimiento (variaciones porcentuales entre todas las variables).

18 Los tres modelos muestran una relación log-lineal.

19 Los datos se tomaron de las siguientes fuentes estadísticas: Para obtener el PIB corriente, PIB constante, la remuneración de asalariados y el número de trabajadores se utilizó la fuente estadística Bureau of Economic Analysis (BEA); los años de educación promedio, se estimaron de la fuente estadística de la OCDE y Barro and Lee; y la experiencia, se obtuvo con cálculos propios en base a datos del Banco Mundial (WDI).

\section{El modelo es log-log.}

21 La prueba de bondad y ajuste mostró los siguientes resultados: Para la relación entre el salario real ( $\mathrm{Ln}$ Wreal) y la educación se obtuvo un $\mathrm{R}^{2}$ de $84.88 \%$, para la relación entre los salarios y la experiencia se obtuvo un $\mathrm{R}^{2}$ de $32.07 \%$; mientras que para la relación del modelo de capital humano en su conjunto se obtuvo un $\mathrm{R}^{2}$ de $85.96 \%$.

22 En la tesis se planteó una ecuación adicional que relaciona el Wr, la CVFT y la tasa de plusvalor.

23 El modelo en general es log-log.

24 El Cuadro 11 muestra una regresión $\log -\log$.

25 En el Cuadro 12 se presenta un modelo $\log -\log$.

26 Ecuación lineal-lineal, refleja cambios en valores absolutos entre las variables.

27 El Cuadro 14 muestra una regresión lineal-lineal con un nivel de confianza del $95 \%$, un $\mathrm{F}$ estadístico de 14976.32 y una medida de bondad de ajuste; es decir, un $\mathrm{R}^{2}$ de $99.69 \%$.

28 El modelo es log-log, por lo tanto, mide los cambios porcentuales en cada una de las variables con respecto a los cambios porcentuales en la productividad.

29 La forma en la cual se calculó la tasa de ganancia fue mediante la tasa de plusvalía (pv') dividida entre la composición orgánica de capital (n) más uno: $T c c g=\frac{p v^{\prime}}{n+1}$. 